\title{
Hybrid Nanocomposite of Imidazolium Based Chitosan and Anderson-type Manganese Polyoxomolybdate for Boosting Drug Delivery Against Breast Cancer
}

Shahrzad Mahvash

Isfahan University of Medical Sciences

Vajihe Azimian Zavareh

Isfahan University of Medical Science

Somayeh Taymouri

Isfahan University of Medical Sciences

Maryam Ramezani-Aliakbari

Isfahan University of Medical Sciences

Fatemeh Dousti

Isfahan University of Medical Sciences

Mina Mirian

Department of pharmaceutical Biotechnology, School of Pharmacy and Pharmaceutical Sciences and, Isfahan

Mahboubeh Rostami ( $\nabla$ m.rostami@pharm.mui.ac.ir)

Isfahan University of Medical Sciences https://orcid.org/0000-0001-9968-821X

\section{Research Article}

Keywords: Anderson-type manganese polyoxomolybdate (MnMo6), Imidazolium modified chitosan (CSIm), Nanocomposite (NC), Anticancer activity, Apoptosis, Cell migration

Posted Date: July 21st, 2021

DOl: https://doi.org/10.21203/rs.3.rs-729081/v1

License: (c) (i) This work is licensed under a Creative Commons Attribution 4.0 International License. Read Full License 


\section{Hybrid nanocomposite of Imidazolium Based Chitosan and Anderson-type manganese Polyoxomolybdate for boosting drug delivery against Breast Cancer}

Shahrzad Mahvash ${ }^{1}$, $(\mathrm{PhD})$, Vajihe Azimian Zavareh $(\mathrm{PhD})^{2}$, Somayeh Taymouri $(\mathrm{PhD})^{3}$, Maryam RamezaniAliakbari $^{1}$ (Master Student) ${ }^{1}$, Fatemeh Dousti (Master Student) ${ }^{1}$, Mina Mirian $(\mathrm{PhD})^{4}$, Mahboubeh Rostami*5 $(\mathrm{PhD})$

${ }^{1}$ Department of Medicinal Chemistry, School of Pharmacy and pharmaceutical Sciences, Isfahan University of Medical Sciences, Isfahan, Iran

${ }^{2}$ Core Research Facilities (CRF), Isfahan University of Medical Science, Isfahan, Iran.

${ }^{3}$ Novel Drug Delivery Systems Research Center and Department of pharmaceutics, School of Pharmacy and Pharmaceutical Sciences and, Isfahan University of Medical Sciences, Isfahan, Iran

${ }^{4}$ Department of pharmaceutical Biotechnology, School of Pharmacy and Pharmaceutical Sciences and, Isfahan, Iran

5*Corresponding Author: Dr. Mahboubeh Rostami: Novel Drug Delivery Systems Research Center and Department of Medicinal Chemistry, School of Pharmacy and Pharmaceutical Sciences and, Isfahan University of Medical Sciences, Isfahan, Iran. E-mail address: $\underline{\text { m.rostami@ pharm.mui.ac.ir }}$

\section{ABSTRACT}

Polyoxometalates (POMs) are a class of inorganic cytotoxic agents with potential anticancer effects. As the nano-formulation is one of the best approaches to adjust the therapeutic effects along with selective delivery, in this study, a novel biocompatible nano-composite (NC) of Anderson-type manganese polyoxomolybdate (MnMo6) was prepared using chitosan conjugate to achieve better selective cytotoxicity profile.

Imidazolium modified chitosan (CSIm) was utilized to get the MnMo6 hybrid NCs (MnMo6@CSIm NCs). The best resulting NCs were evaluated for their anticancer activity against breast cancer cell lines (MCF-7 \& MDA-MB-231) as well as HUVEC normal cells using MTT assay. Furthermore, cellular uptake, apoptosis ratio and cell migration inhibition were evaluated on the MDA-MB-231 cell line as the triple-negative aggressive cell line.

The optimized NPs had a zeta potential above $+27 \mathrm{mV}$ with a uniform distribution of sizes around $145 \mathrm{~nm}$. The loading content and release efficiency were both satisfying (about 44\% and $98 \%$ ). In the release study, a $\mathrm{pH}$-responsive release was detected comparing the neutral conditions.

The NCs had a better anticancer activity than free MnMo6 in both cancer cell lines, without detectable cytotoxicity against HUVEC normal cells. The cellular uptake was about $100 \%$, and apoptosis value was enough high $(81 \%)$ compared to free MnMo6. Interestingly, the MnMo6 hybrid NCs inhibited the cell migration of MDA-MB-231 cell line 1.5 times better than the free MnMo6. All of these results are fascinating to follow more pre-clinical studies on this hybrid NC.

Keyword: Anderson-type manganese polyoxomolybdate (MnMo6), Imidazolium modified chitosan (CSIm), Nanocomposite (NC), Anticancer activity, Apoptosis, Cell migration

\section{INTRODUCTION}

According to a report by GLOBOCAN on 2020, there were 2.3 million women diagnosed with breast cancer and 685000 deaths globally (1). Chemotherapy is still considered the first line of treatment in breast cancer, and Doxorubicin, Cisplatin, Dacarbazine, and Melphalan are some of the most common drugs used in this regard (2). Although chemotherapy has been able to increase the life expectancy of patients to some extent, the non-selectivity of chemotherapy 
drugs leads to severe side effects, which is one of the biggest challenges in cancer chemotherapy (3).

Polyoxometalates (POMs), polyanionic clusters, have been introduced as anti-cancer agents and are considered the next generation of metallodrugs in this area. Several studies have supported the anti-cancer activity of POMs on various cell lines and tumor tissues during years (4). The most studied mechanisms for this activity are disrupting the cell electron transport chains, inducing apoptosis and inhibiting the ATP generation, phosphatase, aconitase, and fibroblast growth factor $(4,5)$. The Anderson-type POMs with the general formula of [Hy(XO6)M6O18]n- $(y=0-6 \& n=2-8)$ is one of the most famous frameworks of POMs, where $\mathrm{X}$ is the central heteroatom (Mn, As, $\mathrm{Si}, \mathrm{P}$ ), and $\mathrm{M}$ is addenda (Mo (VI) or W (VI)) atom respectively (6).

Yamase and co-workers performed some important pioneering works on the anti-cancer activity of POMs in vitro and in vivo (7). After that, the anti-cancer activity of POMs both in free and hybrid conjugate and Anderson-type POMs have been studied several times (4-6, 8). Despite the potential anti-cancer activity of POMs, they have not yet found clinical applications. In this regard, the two main limiting factors are toxicity to normal cells and relatively high IC50s to get an acceptable therapeutic effect (9).

The use of cationic polymeric networks such as chitosan for the better stability and enhanced loading of anionic drugs is a suitable strategy for improving the loading efficiency in a drug and gene delivery system (10).

With the same strategy, a new type of grafted poly (Ionic liquid)s based carrier was designed to controlled drug delivery (11). In a study conducted by Bielas et al. (12), choline-derived ionic liquid monomeric units were successfully introduced with various content in the side chains by controlled radical polymerization for delivery of salicylate. In an aqueous solution, the graft copolymers were self-assembled into spherical nanostructures with sizes up to $73 \mathrm{~nm}$. Proposed nanocarriers had low toxicity against normal human cells (NHDF and BEAS-2B), anti-inflammation activity evaluated with the use of pro-inflammatory interleukins (IL-6 and IL-8) assay and antibacterial activities were determined towards E. coli.

The nano-formulations of POMs via entrapment in polymeric matrixes have been developed to achieve better anti-cancer activity on cancerous cells besides the fewer side effects on healthy cells $(13,14)$. Similarly, as other anti-cancer drugs that take advantage of the nanodrug delivery approach, POMs can be formulated in a nano-platform to overcome both limitations mentioned above. Indeed, nanocarriers with loaded cargo could deliver more selectively to the tumor site without systemic distribution that causes adverse side effects and higher therapeutic dose (15).

As a natural polymer with special characteristic features including low price, bio-compatibility, biodegradability, availability of amine functional group to modification, and $\mathrm{pH}$-sensitivity, chitosan has always been interested in developing nano-formulated dosage forms (16). However, water solubility is a limiting factor in applying chitosan as a biomaterial (17).

Attaching bulky cationic groups to the water-insoluble polymers makes them be solubilize in water more conveniently. So, cationic modified chitosans are promising candidates for considering as carriers for anionic cargos in drug delivery approaches (18).

Quaternized chitosans as cationic modified scaffolds have extraordinary features in drug delivery approaches. Omer et al. (19) reported nanoparticles-based quaternized aminated 
chitosan for curcumin delivery. Another study was conducted by Yang et al. (20) on N-[(2Hydroxyl)-propyl-3-trimethyl ammonium chitosan chloride (HTCC) as a drug carrier for cyclosporine A. Trimethylated chitosan nanoparticles are the most common studied cationic modified chitosan with significant statistics of articles in the field of drug and gene delivery (21).

Due to the anionic identity of POMs, they can be entrapped efficiently in any cationic modified platform. There are some reports on entrapping POMs in cationic frameworks for particular goals, and some of them are related to biomedical applications as follows; Fiorani et al. in 2014, reported the synthesis and characterization of novel nanocomposites derived from commercially available low molecular weight CS and different POMs, including vanadate, molybdate, and tungstate with recognized biological effects, in this regard the antibacterial activity of resulting nanoparticles were tested against E. coli (22).

In another study, Croce et al. in 2018, $\{$ Sb9W21 $\},\{$ P2W18 $\}$ and $\{$ Mo7O24 $\}$ POMs were encapsulated into chitosan and carboxymethyl chitosan (CMC) to give nanoscale composites and the cytotoxicity of free POM and encapsulated POM were investigated on HeLa and MRC5 cell lines, as cancerous and normal cell lines, respectively. Results suggested that encapsulation in CMC enhances the specificity towards cancer cells., their reported IC50s were low enough to be sure about effective therapy in lower prescription doses (23). Saeed Shah et al. (24), and Geisberger et al. (9) reported the same effective strategy for entrapping POMs for anti-cancer activity goals.

In this study, the chitosan imidazolium modified platform (CSIm) with increased cationic identity was used for entrapping the Anderson-type manganese polyoxomolybdate $\left\{\mathrm{MnMo}_{6} \mathrm{O}_{18}\left[\left(\mathrm{OCH}_{2}\right)_{3} \mathrm{CNH}_{2}\right]_{2}\right\}^{3-}\left(\mathrm{MnMo6}^{3}\right)$ cluster for the first time based on strong electrostatic interactions between anionic MnMo6 and cationic modified chitosan as organicinorganic NCs. The complete characterization of NCs was done to ensure potential efficacy, the in vitro cytotoxicity on MCF-7 and MDA-MB-231 cell lines, and HUVEC was studied. The cellular uptake, apoptosis value, and cell migration inhibition were appropriately studied.

\section{EXPERIMENTAL}

\subsection{Materials}

Sodium molybdate (Na2MoO4), Tetrabutylammonium bromide (TBAB), Manganese acetate dihydrate $(\mathrm{Mn}(\mathrm{OAc}) 2.2 \mathrm{H} 2 \mathrm{O})$, glacial acetic acid (GAA), Tris(hydroxymethyl)aminomethane (TRIS), tetramethylammonium btomide (TMAB), Tween 80, and 3-(4,5-dimethylthiazol-2yl)-2,5-diphenyl tetrazolium bromide (MTT) were purchased from Sigma-Aldrich Company (Germany). The MCF-7, MDA-MB-231, and HUVEC cell lines were supplied by the Pasteur Institute (Iran). Trypsin/EDTA, Streptomycin/penicillin, FBS, and RPMI 1640 were purchased from PAA Company (Australia). Annexin V-FITC Apoptosis Detection Kit was purchased from Sigma-Aldrich Company (Germany). All of the other necessary materials and solvents were provided by local vendors and used without further purification.

\subsection{Methods}

\subsubsection{Synthesis of $[\mathrm{TBA}]_{3}\left[\mathrm{MnMo6}_{18}\left\{\left(\mathrm{OCH}_{2}\right)_{3} \mathrm{CNH}_{2}\right\}_{2}\right]$; (TBA-MnMo6)}




\section{- Synthesis of (TBA) $4\left[\alpha-\mathrm{MosO}_{26}\right]($ Step A)}

TBA-MnMo6 was synthesized using previous reports; simply sodium molybdate dehydrate $\mathrm{Na}_{2} \mathrm{MoO} 4 \cdot 2 \mathrm{H}_{2} \mathrm{O}(0.5 \mathrm{~g}, 2.07 \mathrm{~mol})$ was dissolved in distilled water $(2 \mathrm{~mL})$, and the solution was acidified to a $\mathrm{pH}$ of 3 by adding $\mathrm{HCl}$. The reaction mixture was stirred vigorously for several minutes, then a solution of TBAB in water $(0.3 \mathrm{~g} / \mathrm{mL})$ was added to the above solution. After stirring for 10 minutes, the white precipitate was filtered and washed successively with distilled water, ethanol, and diethyl ether. The product, a white powder, was dissolved in acetonitrile, and the obtained colorless cubic crystals were kept overnight at $-10{ }^{\circ} \mathrm{C}$, dried under vacuum, and stored for the final step (C) (25).

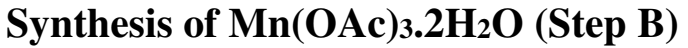

Manganese (III) acetate was prepared based on those reported earlier; briefly, a solution of $\mathrm{Mn}(\mathrm{OAc})_{2} \cdot 4 \mathrm{H}_{2} \mathrm{O}$ in $\mathrm{GAA}$ was heated to $110^{\circ} \mathrm{C}$, and $\mathrm{KMnO} 4$ was added in small portions during 20 minutes. The reaction mixture was cooled, poured into water, and left to crystallize overnight. The brown product was air-dried and stored for the final step (C) (26).

\section{Synthesis of final TBA-MnMO6 (Step C)}

At the final step to get the TBA-MnMO6, a mixture of (TBA) $4\left[\alpha-\mathrm{Mo}_{8} \mathrm{O}_{26}\right]$ (the product of step A) $(8 \mathrm{~g}, 3.7 \mathrm{mmol}), \mathrm{Mn}(\mathrm{OAc})_{3} .2 \mathrm{H} 2 \mathrm{O}$ (the product of step B) $(1.49 \mathrm{~g}, 5.6 \mathrm{mmol})$, and TRIS $(1.56 \mathrm{~g}, 12.8 \mathrm{mmol})$ was refluxed for 16 hours in acetonitrile. The orange solution was filtered to eliminate any black and white precipitates. The large orange crystals were obtained under ether vapor diffusion (a long time was required) and dried under vacuum (27). The chemical structure of TBA-MnMO6 $\left(\left[\mathrm{N}\left(\mathrm{C}_{4} \mathrm{H}_{9}\right)_{4}\right]_{3}\left[\mathrm{MnMo}_{6} \mathrm{O}_{18}\left\{\left(\mathrm{OCH}_{2}\right)_{3} \mathrm{CNH}_{2}\right\}_{2}\right]\right)$ was studied and approved by appearance, FTIR spectrum, and the CHNS elemental analysis method (28). IR $\tilde{v}$ (cm-1): 3448 (N-H str., br), 2960 (C-Hstr., s), 2934 (C-Hstr., s), 1608 (N-Hdef., w), 1479 (s), 1381 (m), 1040 (s), 939 (s, Mo=O), 917 (s, Mo=O), 900 (s, Mo=O), 663 (s, Mo-O-Mo); Elemental analysis: calculated for $\mathrm{C}_{56} \mathrm{H}_{124} \mathrm{MnMo}_{6} \mathrm{~N}_{5} \mathrm{O}_{24}$ : C 35.73\%; $\mathrm{H} 6.64 \%$; $\mathrm{N} 3.72 \%$, Mn $2.92 \%$, Mo 30.59\%; found experimental C 35.73\%; H 6.73\%; N 3.62\%, Mn 2.86\%, Mo 30 . $45 \%$.

\subsubsection{Synthesis of $(\mathrm{Na})_{3}\left[\mathrm{MnMo}_{6} \mathrm{O}_{18}\left\{\left(\mathrm{OCH}_{2}\right)_{3} \mathrm{CNH}_{2}\right\}_{2}\right]$; ( $\left.\mathrm{Na}_{3}-\mathrm{MnMo}\right)$}

Synthesis of (TMA) $)_{2} \mathrm{Na}_{2}\left[\mathrm{Mos}_{26} \mathrm{O}_{26}\right.$ (Step A) $\mathrm{Na}_{2} \mathrm{MoO}_{4} \cdot 2 \mathrm{H}_{2} \mathrm{O}(2.5 \mathrm{~g}, 10.3 \mathrm{mmol}$ ) was dissolved in acidified water $(7 \mathrm{~mL} /(2.5 \mathrm{ml}) 6 \mathrm{M} \mathrm{HCl})$. The reaction mixture was stirred vigorously for several minutes prior to adding an aqueous solution of TMAB $(0.8 \mathrm{~g}, 5.2 \mathrm{mmol}$ in $5 \mathrm{~mL}$ of water). The reaction mixture was stirred vigorously for $10 \mathrm{~min}$, and the resulting white precipitates were collected. It was continuously washed with the same volumes of water, EtOH, acetone and diethyl ether. The (TMA) $)_{2} \mathrm{Na}_{2}\left[\mathrm{Mo}_{8} \mathrm{O}_{26}\right]$, was obtained as a white powder with an average yield based on the Mo content (82\%); elemental analysis: Calculated for $\mathrm{C}_{8} \mathrm{H}_{24} \mathrm{Mo}_{8} \mathrm{~N}_{2} \mathrm{Na}_{2} \mathrm{O}_{26}$ (1377.77 g mol-1): C, 6.97; H, 1.76; N, 2.03; Mo, 55.71 Found: C, 6.85; H, 1.82; N, 1.84; Mo, 55.68; IR $\tilde{v}\left(\mathrm{~cm}^{-1}\right): 3565$ (w, br), 3426 (w, br), 3040 (w, sh), 1268 (m, sh), 1481 (m, sh), 1288 (w, sh), 949 (s, br), 918 (s, br), 841 (s, sh), 664 (vs, br) (29).

Synthesis of $\left.\mathrm{Na}_{3}\left[\mathrm{MnMo}_{6} \mathrm{O}_{18}\left(\mathrm{OCH}_{2}\right)_{3} \mathrm{CNH}_{2}\right)_{2}\right]$, (Na3-MnMo6) (Step B) Compound $(\mathrm{TMA})_{2} \mathrm{Na}_{2}\left[\mathrm{Mo}_{8} \mathrm{O}_{26}\right](0.430 \mathrm{~g}, 0.31 \mathrm{mmol})$ was dissolved in $60 \mathrm{~mL}$ of DMF at room temperature during $30 \mathrm{~min} . \mathrm{Mn}(\mathrm{OAc})_{3} \cdot 2 \mathrm{H} 2 \mathrm{O}(0.127 \mathrm{~g}, 0.47 \mathrm{mmol})$ and TRIS $(0.131 \mathrm{~g}, 1.08$ mmol) were added and the resulting solution was heated up to $80{ }^{\circ} \mathrm{C}$ for $20 \mathrm{~h}$. During the 
reaction some brownish precipitates were settled, after this time, the reaction was cooled to room temperature and the precipitates were removed. The resulting clear orange solution was set up of crystallization at $4{ }^{\circ} \mathrm{C}$ using ether diffusion. The final crystals in this manner were $\mathrm{Na}_{3}-\mathrm{MnMo} 6$ with about $31 \%$ yield based on Mo. The theoretical elemental analysis quantities calculated for $\mathrm{C}_{8} \mathrm{H}_{16} \mathrm{MnMo}_{6} \mathrm{~N}_{2} \mathrm{Na}_{3} \mathrm{O}_{24}$. (DMF)3 (1443.04 g mol-1) were $\mathrm{C}, 14.15 ; \mathrm{H}, 2.58 ; \mathrm{N}$, 4.85; Mn, 3.81; Mo, 39.89 and experimentally were found as C, 13.79.; H, 2.65; N, 4.47; Mn, 3.74; Mo, 39.76; IR: $\tilde{v}\left(\mathrm{~cm}^{-1}\right)=3485(v \mathrm{NH}, \mathrm{m}), 3443(v \mathrm{NH}, \mathrm{m}), 3322(v \mathrm{NH}, \mathrm{m}), 3264(v$ NH, m), 2926 ( $v$ CH, w), 2907 ( $v$ CH, w), $2860(v \mathrm{CH}, w), 1644(\delta \mathrm{NH}, \mathrm{m}), 1601(\delta \mathrm{NH}, \mathrm{m})$, $1465(\delta \mathrm{CH}, \mathrm{m}), 1449(\delta \mathrm{CH}, \mathrm{m}), 1369(\delta \mathrm{CH}, \mathrm{w}), 1317$ ( $v \mathrm{CO}, \mathrm{w}), 1262(v \mathrm{CN}, \mathrm{w}), 1240(v$ $\mathrm{CN}, \mathrm{w}), 1107$ ( $v \mathrm{CO}, \mathrm{m}), 1018(v \mathrm{CO}, \mathrm{s}), 984(\mathrm{~m}), 967(v \mathrm{Mo}=\mathrm{O}, \mathrm{s}), 940(v \mathrm{Mo}=\mathrm{O}, \mathrm{s}), 932(v$ $\mathrm{Mo}=\mathrm{O}, \mathrm{s}), 923(v \mathrm{Mo}=\mathrm{O}, \mathrm{s}), 901(v \mathrm{Mo}=\mathrm{O}, \mathrm{s}), 633$ (vas Mo-O-Mo, s), 558 (vs Mo-O-Mo, m), $521(\mathrm{~m}), 462(\mathrm{~s}), 418(\mathrm{~s})(29)$.

\subsubsection{Synthesis of Imidazolium modified Chitosan- (CSIm)}

Initially, $\mathrm{N}$-methylimidazole $(10 \mathrm{ml}, 0.16 \mathrm{~mol})$ was added dropwise and very slowly to a mixture of 1,2-dichloromethane $(25 \mathrm{ml}, 0.32 \mathrm{~mol})$ in acetone $(25 \mathrm{ml})$ at room temperature. The resulting mixture was stirred for 48 hours at $75^{\circ} \mathrm{C}$. When the reaction is completed, the product precipitates will be obtained by adding ethanol to the reaction mixture. In the next step, it was washed with anhydrous ethanol and dried under vacuum at $80{ }^{\circ} \mathrm{C}$. The chemical structure of this conjugate was confirmed by FTIR and ${ }^{1} \mathrm{HNMR}$ spectra (30).

\subsubsection{Preparation of MnMo6@CSIm NCs Using Na3-MnMo6 (MnMo6@CSIm-A)}

MnMo6@CSIm NCs in this manner were synthesized by dissolving $0.50 \mathrm{~g}$ of CSIm in $50 \mathrm{~mL}$ $0.1 \%$ acetic acid solution. The resultant solution was filtered to remove residues. Similarly, 0.5 $\mathrm{g}$ of $\mathrm{Na}_{3}-\mathrm{MnMo}_{6}$ was dissolved in $25 \mathrm{~mL} \mathrm{H2O}$, this solution was added dropwise into the CSIm solution. After a while (30 min.), precipitates were separated by filtration and washed several times with water and air-dried. The final product was characterized by FTIR and 1HNMR spectroscopy, furthermore, TGA and ICP-Ms analysis were done to determine the loading content of poltoxometalate (24).

\section{Using TBA-MnMo6 (MnMo6@CSIm-B)}

CSIm was dispersed in $0.1 \%$ acetic acid solution and stirred for 1 day at $80{ }^{\circ} \mathrm{C}$. The obtained solution of CSIm was filtered to remove undissolved particles. We used $0.25 \%$ Tween 80 to prevent nanoparticle agglomeration. In order to prepare MnMo6 nanohybrid (MnMo6@CSIm), a solution of TBA-MnMo6 $(5 \mathrm{~mL}, 10 \mathrm{mg} / \mathrm{mL})$ in slightly acidified (pH of 6) water solution -acetonitrile, was added to $5 \mathrm{~mL}(10 \mathrm{mg} / \mathrm{mL})$ of CSIm followed by stirring for $12 \mathrm{~h}$. After that, the resulting mixture was dialyzed against water containing $0.25 \%$ tween 80 to remove the unbounded MnMO6 nanoclusters or TBA for $24 \mathrm{~h}$. The resulting solution was lyophilized, and the precipitates were stored for further analysis $(31,32)$. The chemical 
composition of this nano-composite was approved by FTIR, ${ }^{1} \mathrm{HNMR}$ spectroscopies, furthermore the loading content was determined using ICP-Ms, and TGA.

It should be noted that the blank NCs were prepared by TPP as crosslinker based on previous reports (22) for comparing the results.

\subsubsection{DLS studies}

The hydrodynamic size (HS), zeta potential (ZP), and PDI for both prepared (NCs) were determined by a laser light scattering technique (DLS) using a particle size analyzer (Zetasizer, ZEN 3600, Malvern Instrumental, UK). Thus, a dispersion of NCs with $40 \mu \mathrm{g} / \mathrm{mL}$ concentration in deionized water was prepared freshly. The measurements were repeated three times at room temperature, and the average was reported as mean \pm standard deviation (SD)(33).

\subsubsection{Thermogravimetric analysis (TGA)}

Thermogravimetric analyses for Na3-MnMo6, TBA-MnMo6, CSIm and resulting NCs were done using TA instrument SDT Q600 system. Powdered samples $(5 \mathrm{mg})$ were used for analysis at a temperature range from ambient to $800{ }^{\circ} \mathrm{C}$. Analysis was performed under nitrogen gas purging at a flow rate of $100 \mathrm{~mL} / \mathrm{min}$ with the heating rate adjusted at $20^{\circ} \mathrm{C} / \mathrm{min}$.

\subsubsection{Morphological Analysis}

The morphology and the exact size of NPs were obtained using transmission electron microscopy (TEM) (JEOL-100CXII, Japan) in the power of $26.0 \mathrm{kV}$. TEM images were obtained by a drop casting the NCs colloidal dispersion on copper grids (300 mesh). After airdrying, the grids were incubated, then, they were visualized by magnification of $\times 1000(34)$.

\subsubsection{Loading content and entrapment efficiency of MnMO6 in CSIm NPs}

After preparing the NPs (MnMo6@CSIm-A) and (MnMo66 CSIm-B), the Mo content as representative of loaded MnMo6 was determined by ICP-Ms technique and the loading content (LC \%) and entrapment efficiency (EE \%) of MnMo6 was determined using the following equations (35):

$$
\begin{aligned}
& \text { LC } \%=\frac{W_{\text {MnMO6 }}}{W_{t}} \times 100 \\
& \text { EE } \%=\frac{W_{\text {POMo }}}{W 0_{\text {POMo }}} \times 100
\end{aligned}
$$

\subsubsection{In vitro drug release}

To study the in vitro release of MnMO6 from the prepared NCs, $5 \mathrm{mg}$ of freeze-dried powder was dispersed in $3 \mathrm{~mL}$ of phosphate buffer saline (PBS-10 mM) and transferred to a dialysis bag (MW cutoff; $12 \mathrm{KDa}$ ) and immersed in $20 \mathrm{~mL}$ of PBS with $0.1 \%$ of tween 80 at pH of 7.4, and 5. The evaluations were done at $37^{\circ} \mathrm{C}$ in a bain-marie shaker (120 rpm for $20-30 \mathrm{~h}$ ). At predetermined time intervals, $2 \mathrm{~mL}$ of the media was taken and replaced with fresh PBS, and the 
amount of released MnMO6 determined by UV-Vis. Spectroscopy $\left(\lambda_{\max }=210 \mathrm{~nm}\right)$. The cumulative concentration of MnMO6 at each time was calculated according to the standard calibration curve obtained for MnMO6 in PBS-2\% of tween 80 at $210 \mathrm{~nm}$ (36) using following equation:

$R_{P O M o} \%=\frac{C_{n} \times V+V_{n} \sum_{0}^{n} C_{i}}{W_{N P} \times L C \%} \times 100$

Where $\mathrm{W}$ was the weight of NPs; $\mathrm{C}_{\mathrm{n}}$ was the concentration at $\mathrm{t}_{\mathrm{n}}$; V was the total volume of dialysis medium; $\mathrm{V}_{\mathrm{n}}$ was the volume of the each taken sample $(1 \mathrm{~mL})$; and $\mathrm{C}_{\mathrm{i}}$ was the concentration of taken sample at $\mathrm{t}_{\mathrm{i}}(0,0.5,1,2,4, \ldots, 48 \mathrm{~h})$ both $\mathrm{V}_{0}$ and $\mathrm{C}_{0}$ are equal to zero.

\subsubsection{In vitro colloidal stability study}

The colloidal stability of aqueous dispersions was investigated in cell culture media (RPMI) with $15 \%$ FBS, and blood serum at $300 \mu \mathrm{g} / \mathrm{mL}$ concentration of MnMO6@CSIm. The colloidal samples were incubated for $1 \mathrm{~h}, 4 \mathrm{~h}$ and $24 \mathrm{~h}$ at $37^{\circ} \mathrm{C}$. After predetermined time points, one $\mathrm{mL}$ of each sample was diluted in $4 \mathrm{~mL}$ PBS and the size of NPs (without sonication) was determined by DLS measurement using a Zetasizer (NanoZS, Malvern Instruments, UK) (37).

\subsubsection{In Vitro Biological Assessments}

\subsubsection{Cell culture}

Breast cancer cell lines (MCF-7 and MDA-MB-231), and normal human umbilical vein endothelial cell line (HUVEC) were used to evaluate the cytotoxicity of MnMO6@CSIm in compare to free Na3-MnMO6, and the blank NCs. The MCF-7 and MDA-MB-231 cells were cultured in RPMI 1640 medium and HUVEC cultured in DMEM-F12 containing 10\% fetal bovine serum (FBS), $1 \%$ penicillin/streptomycin at $37^{\circ} \mathrm{C}$ under a fixed humidity with $5 \% \mathrm{CO} 2$ (38).

\subsubsection{Cell Growth Inhibition Assays}

The MTT method was used to evaluate the cytotoxicity of Na3-MnMO6, MnMO6@CSIm-A on MCF-7, MDA-MB-231(as breast cancer cell lines), and HUVEC cells. 180 $\mu \mathrm{L}$ of cell suspension (density $5 \times 10^{4}$ cells per $\mathrm{mL}$ ) were seeded into 96-well plates and allowed to incubate for $24 \mathrm{hrs}$. For Na3-MnMO6, the $20 \mu \mathrm{L}$ of different concentrations ranging from 25 to $300 \mu \mathrm{g} / \mathrm{mL}$ (concentration in the vicinity of cells) in medium (with $1 \%$ DMSO) were added to the wells, and for NPs, the culture medium was replaced with the freshly prepared samples of MnMO6@CSIm with concentrations of 100 to $300 \mu \mathrm{g} / \mathrm{mL}$. Using initial evaluations on incubation times $(24$, and $48 \mathrm{~h}$ ) to get the best cytotoxicity profile, $48 \mathrm{~h}$ was selected as the suitable incubation time for further studies. After $48 \mathrm{~h}, 20 \mu \mathrm{L}$ of MTT solution in PBS (5 mg/ $\mathrm{mL}$ ) was added to each well and incubated for $4 \mathrm{hrs}$. Next, the medium was eliminated, and formazan crystals were dissolved in DMSO $(150 \mu \mathrm{L})$, and the absorbance of each well was obtained using an ELISA reader at $570 \mathrm{~nm}$. The values were expressed in percentage relative to the controls. The cell viabilities were calculated by following equation (39):

$$
C V(\%)=\frac{M_{a b s .} \text { of } T G-M_{a b s .} \text { of } B}{M_{a b s .} \text { of } N C-M_{a b s .} \text { of } B} \times 100
$$


Where: CV means cell survival; $\mathrm{M}_{\text {abs }}$ refers to mean absorption; TG means treatment group; $\mathrm{B}$ refers to Blank; and NC refers to negative control.

\subsubsection{Cellular uptake Studies by ICP-mass analysis}

The MDA-MB-231 breast cancer cells were grown in $75 \mathrm{~cm}^{2}$ culture flasks at $37{ }^{\circ} \mathrm{C}$ in $5 \%$ $\mathrm{CO} 2$ atmosphere until at least $80 \%$ confluency. The medium was removed and replaced with $14 \mathrm{~mL}$ RPMI-15\% FBS and 1\% DMSO containing the compounds, $\mathrm{Na}_{3}-\mathrm{MnMO}$, and MnMO6@CSIm-A in a concentration of 300 $\mathrm{g} / \mathrm{mL}$. After $48 \mathrm{~h}$ incubation at mentioned condition, the medium was removed and the cells were washed with $10 \mathrm{~mL}$ PBS (three times) then detached by trypsinization and resuspended in $10 \mathrm{~mL}$ PBS (pH 7.4). The suspension of cells was centrifugated (2000 rpm, $5 \mathrm{~min}$ ) and the isolated pellets washed twice with ice-cold PBS. The isolated pellets were resuspended in $500 \mu \mathrm{L}$ deionized water and the cells lysed using a sonotrode. For protein determination by the Bradford method, an aliquot of each lysate samples was stored at $-20{ }^{\circ} \mathrm{C}$. The lysates were digested by the addition of $15 \mu \mathrm{L}$ of $\mathrm{HNO}_{3}(10 \%)-\mathrm{HCl}(30 \%)$ and $15 \mu \mathrm{L}$ of Triton X-100 (1\%) for their molybdenum content determination by ICP-Ms spectroscopy. The cellular Mo concentrations were expressed $\mu \mathrm{g}$ Mo per $\mu \mathrm{g}$ cellular protein $(40,41)$.

\subsubsection{Apoptosis analysis}

The annexin V staining used to test apoptosis, briefly, MDA-MB-231 cells were seeded in 6well $\left(3 \times 10^{5}\right.$ per well) plates and after incubation for $24 \mathrm{~h}$, the media was replaced with MnMo6 and MnMo6@CSIm-A NCs dispersions at a concentration of $200 \mu \mathrm{g} / \mathrm{mL}$ based on MnMo6 content, and the cells were incubated for another $24 \mathrm{~h}$. Cells were collected and washed twice with cold PBS, stained for 15 min with annexin-V-FITC $(5 \mu \mathrm{L})$ and propidium iodide $(5 \mu \mathrm{L})$ then the degree of apoptosis was quantified using FACS calibur flow cytometer $(\mathrm{Ex}=488 \mathrm{~nm}$; $\mathrm{Em}=350 \mathrm{~nm})(42)$.

\subsubsection{Cell migration assay}

$10^{6}$ cells were seeded in DMEMF-12 culture medium with $10 \%$ FBS in 6 wells plate, allowed to attach and reach confluency. Then cells were serum starved for an overnight, after that, culture medium was removed and scratch was made through the confluent monolayer using a sterile pipette tip. Cells were washed twice with PBS to remove floating cells and debris, and finally DMEMF-12 medium without serum or with 2\% FBS (with or without drugs, as control and test group respectively) was added. The distance of the wounded areas at referenced locations and at intervals of $0,3,6,9,12$ and $24 \mathrm{~h}$ was observed under a microscope at $4 \mathrm{x}$ magnification. The wound gap was measured, and the percent wound closure was determined for each time point. All treatments were assessed in triplicate (43).

$$
\text { cellular Migration } \%=\frac{\mathrm{A} 0-\mathrm{At}}{\mathrm{A} 0} \times 100
$$

Where, $A_{0}$ refers to the distance was measured at 0 hours and $A_{t}$ means the distance was measured at $\mathrm{t}$ time.

\subsubsection{Red blood cell hemolysis}


In this study, the whole blood samples were obtained from Isfahan Blood Bank in heparinized tubes. At first, the blood sample was centrifuged at $3000 \mathrm{rpm}$ for 5 minutes to separate the serum and RBCs. The RBCs were washed with a sterile isotonic $0.9 \% \mathrm{NaCl}$ solution and suspended in the same isotonic solution, with a ratio of 1:20 (RBC: isotonic $0.9 \% \mathrm{NaCl}$ solution). The MnMo6 and MnMo6@CSIm (in situ) were dispersed in the $0.9 \% \mathrm{NaCl}$ isotonic solution in a $300 \mu \mathrm{g} / \mathrm{mL}$ concentration separately. Then, $1 \mathrm{~mL}$ of colloidal solutions were added to tubes containing $1 \mathrm{ml}$ of the RBCs suspension (final concentration of nanoparticles was 150 $\mu \mathrm{g} / \mathrm{mL})$. To prepare the positive (100\% hemolysis) and negative ( $0 \%$ hemolysis) controls, $1 \mathrm{~mL}$ of RBC suspensions were mixed with $1 \mathrm{~mL}$ of deionized water and isotonic $0.9 \% \mathrm{NaCl}$ solution, respectively. After $4 \mathrm{~h}$ incubation at $37 \pm 1{ }^{\circ} \mathrm{C}$ by shaking in a water bath, the tubes were centrifuged at $3000 \mathrm{rpm}$ for $5 \mathrm{~min}$ and the absorbance of the supernatants was measured using UV-Vis spectroscopy at $540 \mathrm{~nm}(44,45)$. To calculate the hemolysis percentage, we used the following formula all of measurements were triplicated:

$$
\text { Hemolysis }(\%)=\frac{A_{S}-A_{N C}}{A_{P C}-A_{N C}}
$$

Where, As refers to absorption of sample; $\mathbf{A}_{\mathbf{N C}}$ means the absorbance of negative control; and APC means absorption of positive control.

\subsection{Statistical analysis}

All tests were triplicated for each sample and the average \pm SD (standard deviation) was reported as the result. Data were analyzed using one-way ANOVA followed by student t-test (paired or unpaired) using SPSS software (version of 21) to evaluate the difference between the groups or Post Hoc LSD test for more than two groups. The difference between averages would be significant if $\mathrm{p}<0.05$.

\section{Results and Discussions}

\subsection{Synthesize and characterization}

In this study for the first time, we report the Anderson-type manganese polyooxomolybdate (MnMo6) chitosan imidazolium nanocomposite (MnMo6@CSIm NCs) as anti-cancer agent. The MnMo6 anionic cluster as the cytotoxic agent candidate was synthesized using a hydrothermal process starting from sodium molybdate in acidic conditions. In this regard, two types of salts comprising sodium salt and TBA salt were synthesized and used thereafter (29, 46). To get the modified and optimized formula, we prepared the NCs using both sources of salts. In the first class, we prepared the NCs based on the ability of Na-MnMo6 as an anionic cluster to induce strong crosslinking pattern within cationic polymeric network in a direct path. In the other approach, we utilized the cation exchange strategy to prepare the final NCs. In both procedures the result was the same; in fact, MnMo6 involves as crosslinker in developing nanocomposites such as those routinely report for TPP in constructing chitosan nanoparticles (47).

$$
\text { Na3 - MnMo6 + CSIm } \stackrel{A}{\rightarrow} \text { MnMo6@CSIm - A NCs }
$$




\section{$T B A 3-M n M o 6+C S I m \stackrel{B}{\rightarrow} M n M o 6 @ C S I m-B N C s$}

A: Direct path $\mathrm{MnMo}_{6}$ as crosslinker; B: MnMo6 as crosslinker via a cation exchange strategy using dialysis

Since the synthesis of MnMo6 based clusters has been reported several times before even in our recent works $(28,48)$, FTIR spectrum and appearance of crystals as well as CHNS elemental analysis were used to approve the chemical structure.

In FTIR spectra of products (figure 1) in compare to the subunits, all of the characteristic stretching and vibrating bands were located correctly. By carefully examining the FTIR spectrum of components, we discover the specific spectral details of each of them, which can help us evaluate and validate the product structure based on the final spectrum.

The stretching bands for metal-oxygen bonds at 561, 662, 918, and $940 \mathrm{~cm}-1$ are the best proof for TBA-MnMo6 structure. Other reference bands of TBA residues were located around 2900 $\mathrm{cm}-1, \mathrm{C}-\mathrm{H}$ stretches of methyl groups were detected at $2934 \mathrm{~cm}^{-1}$, the bending of methyl groups at $1380 \mathrm{~cm}-1$. All of these proofs were in good agreement with other previous reports $(27,49)$. In the same manner characteristic stretching and bending bands for Na3-MnMo6 structure were appeared in the right places as available evidences reported. Especially $\mathrm{Mo}=\mathrm{O}$ strong stretching bands around 967, 940, 932, 923, and $901 \mathrm{~cm}-1$, as well as Mo-O-Mo strong stretching bands which were located at around $633,558,521,462$, and $418 \mathrm{~cm}-1$ were in good agreement with other available reports (29). In the FTIR spectrum of the CSIm polymer conjugate, specific chitosan adsorption bands have appeared with some changes in the appropriate spectral range. The presence of absorption bands in region 1660 and around $3070 \mathrm{~cm}^{-1}$, which are related to the stretching vibrations of the imidazolium ring, are good evidence for confirming the conjugate structure of CSIm based on available references (50). The stretching bands around $3440 \mathrm{~cm}-1$ are corresponded to $\mathrm{C}-\mathrm{H}$ bonds, and the absorbances at $1650 \mathrm{~cm}-1$ and $1043 \mathrm{~cm}-1$ are characteristic features of $\mathrm{C}=\mathrm{O}$ and $\mathrm{N}-\mathrm{H}$ bending modes.

A closer look at the FTIR spectra of the products reveals the absorption bands of the components, although for the $\mathrm{MnMo}_{6}$ core absorption bands we see a decrease in the adsorption intensity, which can be due to its entrapment within the nanocomposite structure and lack of full access.

We used the ${ }^{1}$ HNMR spectra for approving the presence of both sub-structures in the final NCs. As figure 2 depicts, the characteristic signals of MnMo6 have been appeared around 62 ppm which belongs to the TRIS moiety of inorganic core. The presence of imidazolium aromatic features of CSIm have been approved by signals around 7-8 ppm. In the final composite, the spectral proofs of CSIm and MnMo6 have been clearly detected in the correct places as shown in figure. 


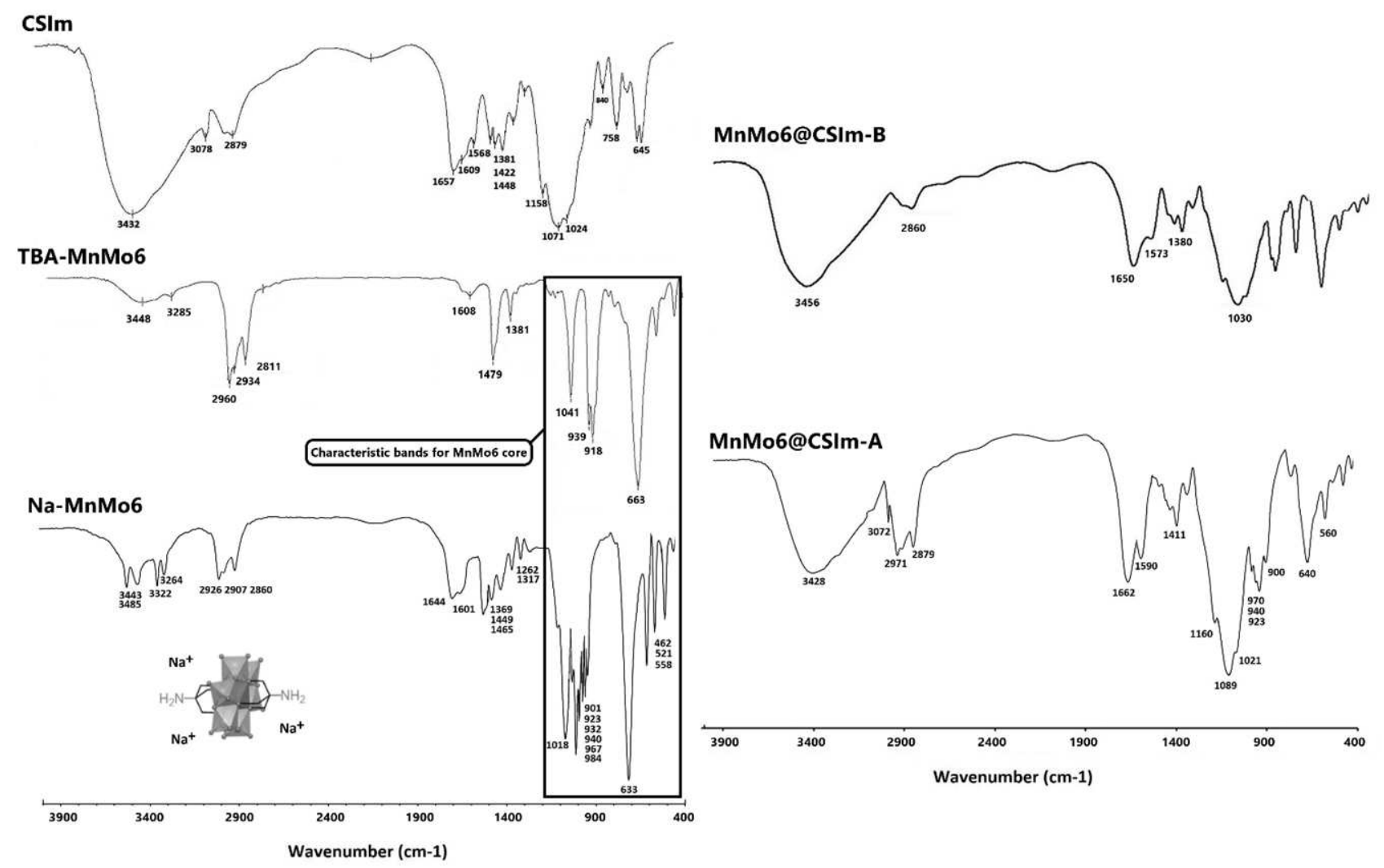

Figure1: the FTIR spectra of CSIm, TBA-MnMo6, Na-MnMo6, MnMo6@CSIm-A, and MnMo6@CSImB NCs 


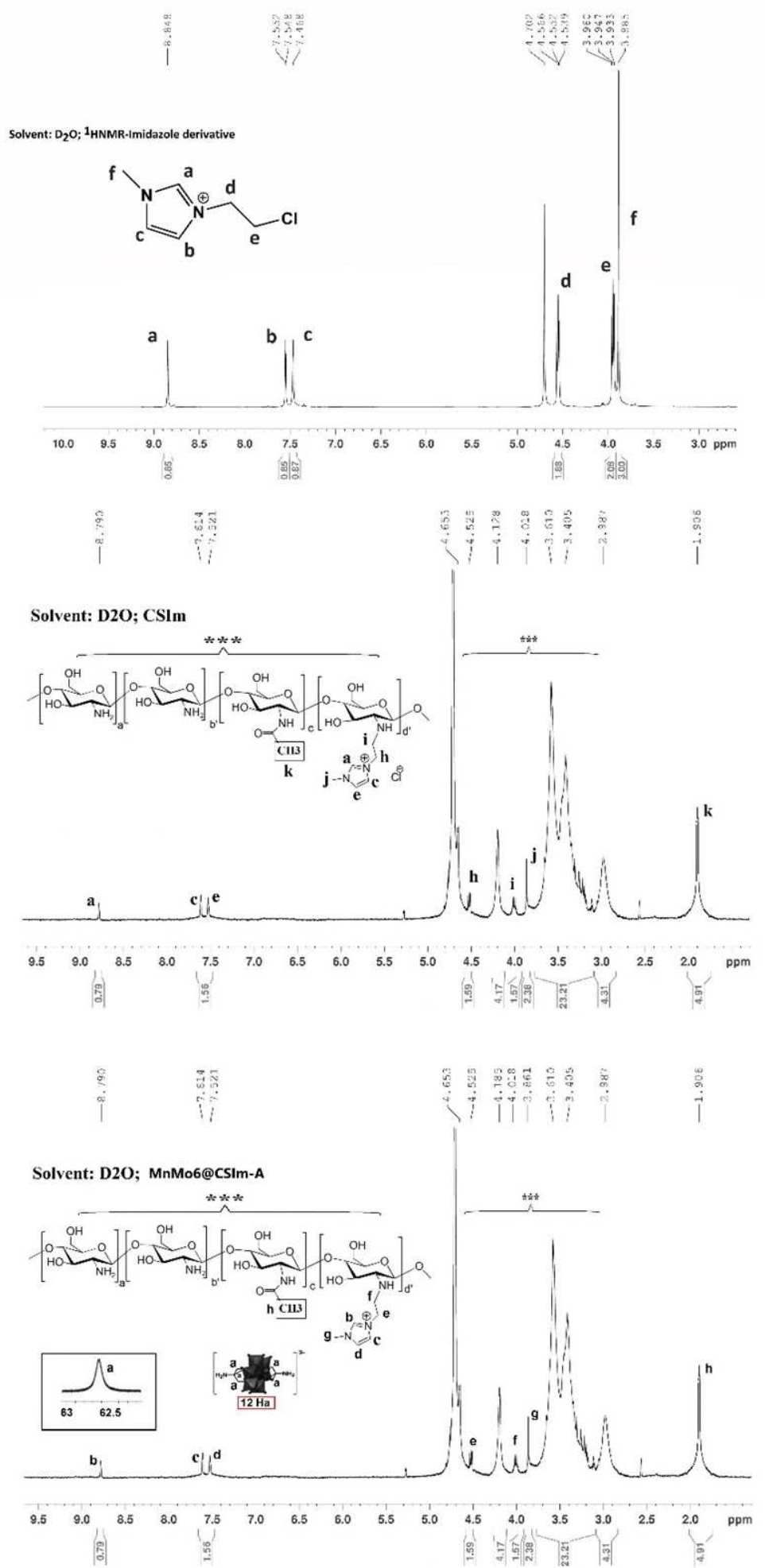

Figure 2: ${ }^{1} \mathrm{HNMR}$ spectra of ImCl, CSIm, and MnMo6@CSIm-A

Figure 3 shows the TGA for Na-MnMo6, CSIm, MnMo6@CSIm-A (part A), and CSIm, TBAMnMo6, MnMo6@CSIm-B (part B) NCs. As shown in Figure 3A, CSIm started showing a sharp decrease in weight around $200^{\circ} \mathrm{C}$, which is due to the decomposition of the imidazole 
ring [32]. The weight decreasing has continued gradually and almost all of the weight has been lost until $800{ }^{\circ} \mathrm{C}$. However, the profile was completely different in the case of Na-MnMo6, TBA-MnMo6 and their final composites.

The thermal weight behavior of the evaluated salts in the considered temperature range depends on their organic structural components and the loss of cross-links of metal oxides. These changes are associated with the loss of the cationic fraction for tetrabutylammonium salts at temperatures of about $300-380{ }^{\circ} \mathrm{C}$ (35.5\%; theoretical value was $\left.38 \%\right)$, and then we observe approximately the same behavior for both salts at temperatures above $450{ }^{\circ} \mathrm{C}$. In the temperature range of $450{ }^{\circ} \mathrm{C}$, TRIS moieties have been decomposed, and at temperatures above $650^{\circ} \mathrm{C}$, we face weight loss with the loss of transverse oxygen bridges within the mineral structure (51). For the product route- $\mathrm{A}$, the residual mineral content up to $650{ }^{\circ} \mathrm{C}$ and above is about $45 \%$, while for the route-B it is about $38 \%$.

A noteworthy point is the percentage of TBA organic cations within the structure of the TBA salt and the percentage of the same TRIS fraction in both salts, which is another confirmation of the correctness of the chemical structure of these salts. 

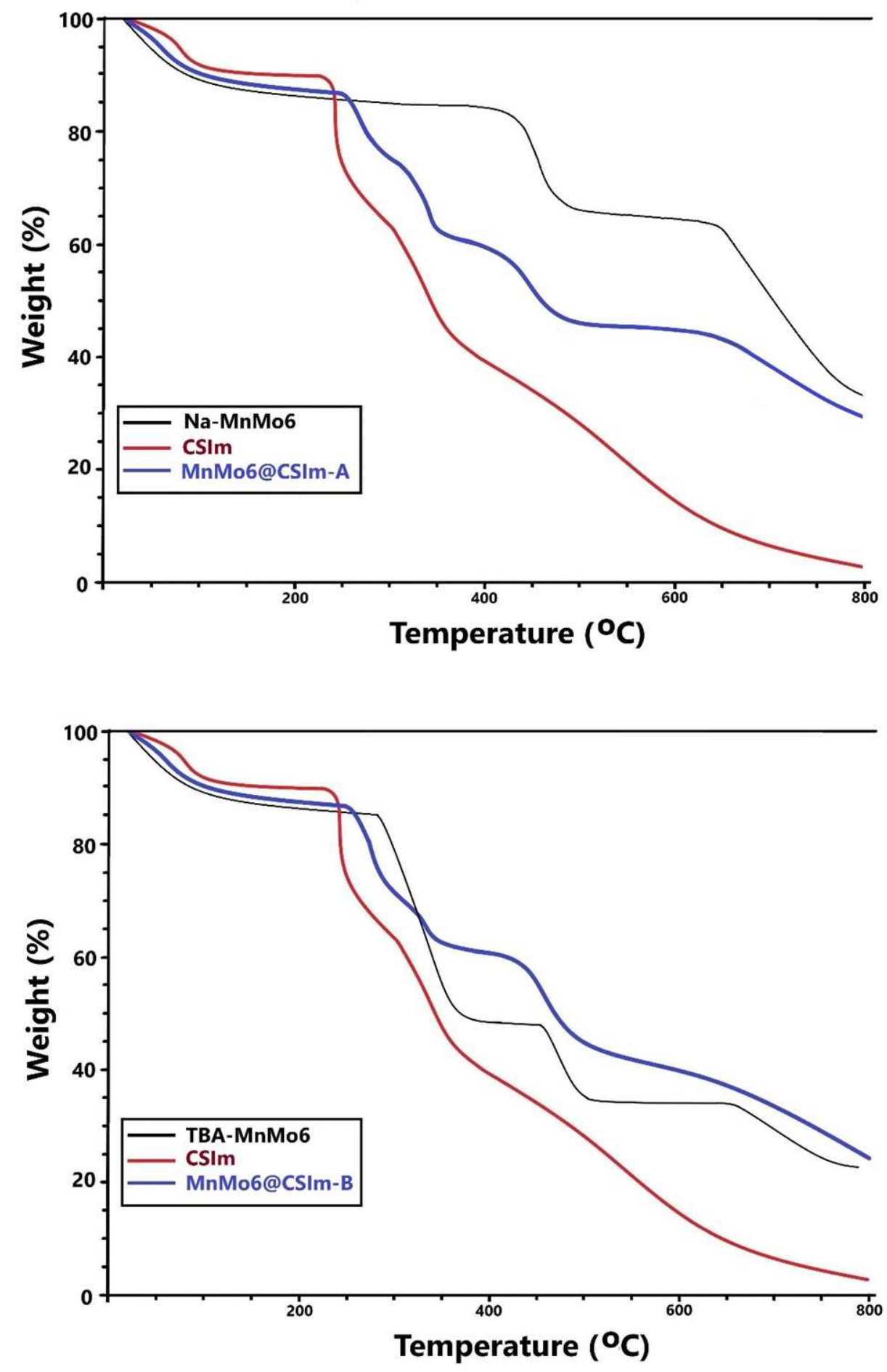

Figure 3: TGA diagram for two different type of NCs (up: MnMo6@CSIm-A; and down: MnMo6@CSImB) in compare to their subunits 


\subsection{Preparation and characterization of NCs}

\subsubsection{Hydrodynamic Size \& Zeta potential}

There are several biological barriers in the body against any foreign agents (52); in this regard, the particle size is the most critical factor to overcome biological barriers. Abnormal angiogenesis and "enhanced permeability and retention" (EPR) effect help nano-sized drug delivery systems to accumulate in cancer tissue, so that the size can have a significant role in passive targeting. According to DLS measurements (Table 1), for all evaluated NCs including MnMo6@CSIm-A, and MnMo6@CSIm-B, the hydrodynamic sizes were less than 200 nanometers.

In type A of NCs, the sizes are significantly smaller, which seems to be due to the absence of relatively bulky TBA cations, which allow the structure to be compressed to achieve maximum intra-structural interactions. In type A of NCs, at the same time of mixing, it appears that more and stronger crosslinks have been created, but in the case of pathway $b$ species at the same time, conditions may not have been provided for the replacement of larger cations at the head of the branches. In general, the structure has not had enough time for proper twisting and therefore the hydrodynamic diameter is relatively larger.

It is noteworthy that compared to nanoparticles formed with TPP crosslinkers, the sizes in category A are significantly smaller (140 nm Vs $167.4 \mathrm{~nm}$ ), indicating that the MnMo6 anion has a stronger action.

Zeta potential is one of the critical factors affecting the micelle stability and is a correct representative of the surface charge. In fact, with increasing the zeta potential in nanoscale, the particles repel each other, and the tendency to agglomeration decrease drastically; this condition gives more stable suspension (53).

The zeta potential of the resulting NCs is positive and numerically greater than $22 \mathrm{mV}$, which can be a sign of colloidal stability of these nanoparticles.

The results of loading, size, zeta and polydispersity index were all in favor of nanocomposites prepared by method $\mathbf{A}$ and therefore in subsequent evaluations only this system was considered as the optimal system.

\subsubsection{MnMo6 loading content (LC \%) and encapsulation efficacy (EE \%)}

Drug entrapment efficiency (EE) and drug loading content (LC) (54) are the most important criteria for success in a drug delivery approach for POMs agents with relatively higher IC50 values (55). Achieving a higher loading content than a higher loading efficiency is usually a challenge for nanoparticles, and in most nanoparticles, it falls below $40 \%$. Neutral carriers lead to a sharp decrease in this number (often below 10\%), which requires large amounts of nanoparticles to achieve an effective therapeutic dose at the target site $(56,57)$.

Therefore, achieving nanoparticles with high loading content is an ideal goal in the design of drug delivery nanoparticles. In this design, the selected carrier was CSIm cationic polymer conjugate, which has a very high potential for anionic drug loading due to its cationic groups, thus results interestingly in high loading content. content results. The loading content was measured for prepared NCs by ICP-MS basically. The Loading percentage of the optimal NCs have been 
reported in table in Table 2, proper drug loading (>43\% for MnMo6@CSIm-A NCs) can be attributed to the electrostatic interaction between the nanoparticle matrix and the MnMo6 drug functional groups. The amount of space that is available for drug bonding and drug stability within nanoparticles are the most important parameters for optimizing drug loading (58).

Table 1. Optimization of effective parameters on nanoparticle preparation

\begin{tabular}{|l|c|c|c|}
\hline \multicolumn{1}{|c|}{ Formulation } & HS (nm) & ZP (mV) & PDI \\
\hline MnMo6@CSIm-A & $140.1 \pm 1.9$ & $27.3 \pm 2.0$ & 0.36 \\
\hline MnMo6@CSIm-B & $167.4 \pm 1.8$ & $26.1 \pm 1.2$ & 0.50 \\
\hline CSIm-TPP & $162.1 \pm 2.3$ & $22.7 \pm 1.5$ & 0.65 \\
\hline
\end{tabular}

All experiments were triplicated at $37^{\circ} \mathrm{C}$ and reported as mean \pm SD; PDI: Poly Dispersity Index; ZP: Zeta potential; HS: Hydrodynamic Size

Table 2. evaluation of EE and LC of nanoparticle; EE: Entrapment Efficiency; LC: Loading content

\begin{tabular}{|l|c|c|}
\hline Formulation & EE\% $\mathbf{\text { SD }}$ & LC\% \pm SD \\
\hline MnMo6@CSIm-A & $97.50 \pm 0.10$ & $43.50 \pm 0.10$ \\
\hline MnMo6@CSIm-B & $95.10 \pm 0.20$ & $41.05 \pm 0.22$ \\
\hline
\end{tabular}

\subsection{TEM images}

Finally, the nanoparticle size and morphology were carefully studied using TEM images (Figure 4); based on the image, MnMo6@CSIm-A have a spherical shape and approximately $100 \mathrm{~nm}$ diameters. As the figure implies, compared to the size obtained by DLS in the solution phase (140 $\mathrm{nm}$ ), the size is somewhat smaller in the solid-state. It can be explained entirely by the hydration of particles in the solution phase; indeed, in the aqueous solution, average hydrodynamic particle diameters obtained using the Einstein-Stokes's equation. Furthermore, beside the spherical particulate shape, the drug loading was observed to some extent in the obtained image $(24,59)$. 


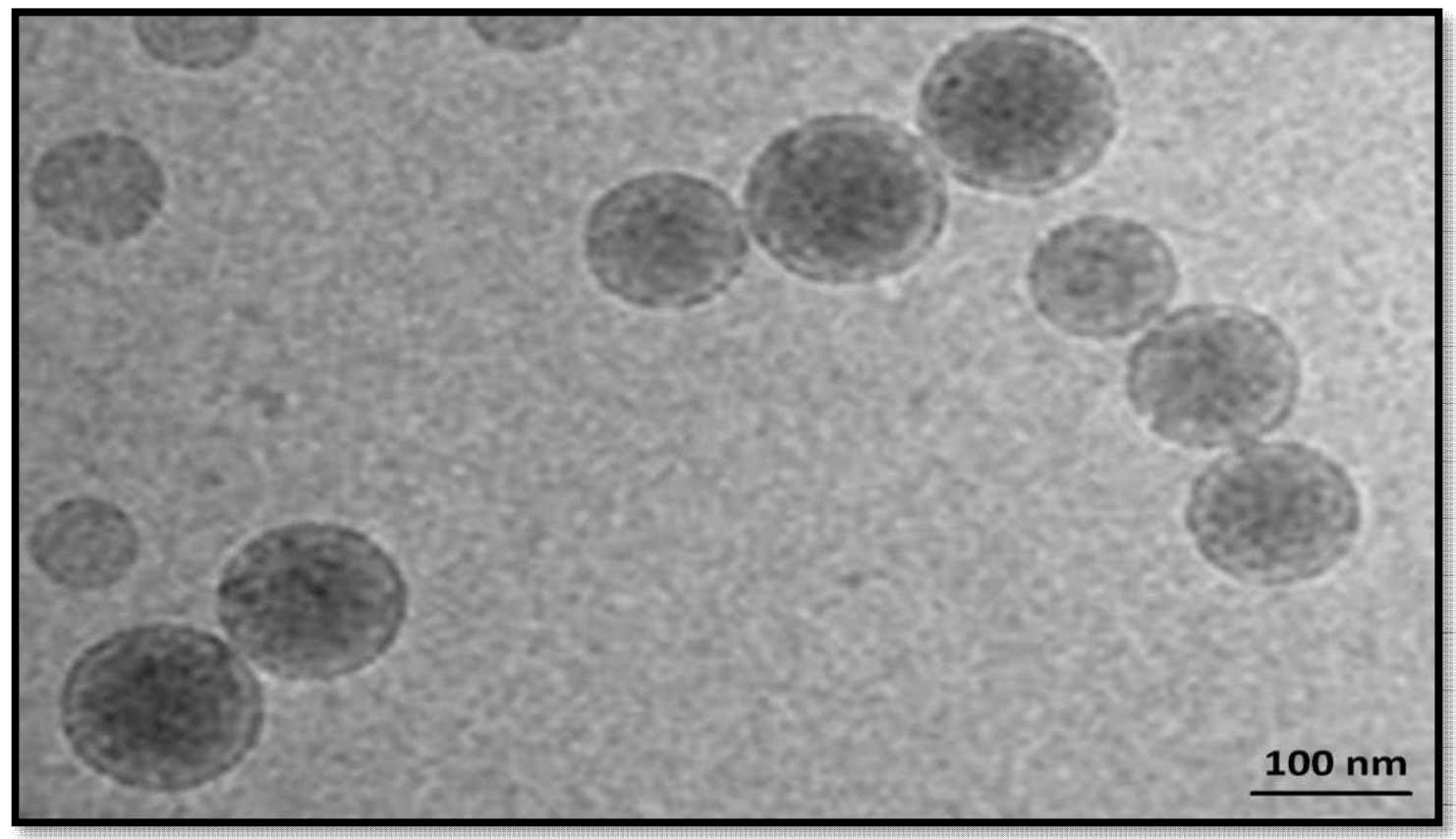

Figure 4. The TEM image of MnMo6@CSIm nanoparticle

\subsection{In vitro drug release}

The release behavior of MnMo6@CSIm-A NCs, was investigated in two different pHs (7.4 \& 5) of phosphate buffer saline with $0.1 \%$ Tween for $48 \mathrm{~h}$, and the results have provided in figure 5 . Based on the evidence, the environment of tumor tissues has a relatively lower $\mathrm{pH}$ due to the higher metabolism, and this condition is more common in the lysosomal area (60). Because of cationic pendant groups and other amine groups within the polymer network, it was expected the prepared nanoparticle provide a response to the $\mathrm{pH}$ triggers and make the higher release profile (61).

As it expected, the release of MnMo6 from the prepared nano-formulation (Figure 5) shows a pHdependent behavior. Release at a $\mathrm{pH}$ of 7.4 is slower than the acidic condition $(\mathrm{pH}=5)$. In the first hour, about $5.6 \%$, and $20.4 \%$ of the drug was released at $\mathrm{pH}$ of 7.4 , and $\mathrm{pH}$ of 5 , respectively. Totally, after $48 \mathrm{~h}, 98.5 \%$ of MnMo6 was released at acidic $\mathrm{pH}$ and $40 \%$ at physiologic $\mathrm{pH}$ in a sustained manner. According to the significant difference ( $\left.p_{\text {value }}<0.05\right)$ between the MnMo6 released percent at all times, the MnMo6@CsIm-A NCs with a pH-sensitive behavior are an efficient system for delivery of this cytotoxic agent to the cancerous cells, especially at acidic conditions within the lysosome (62). 


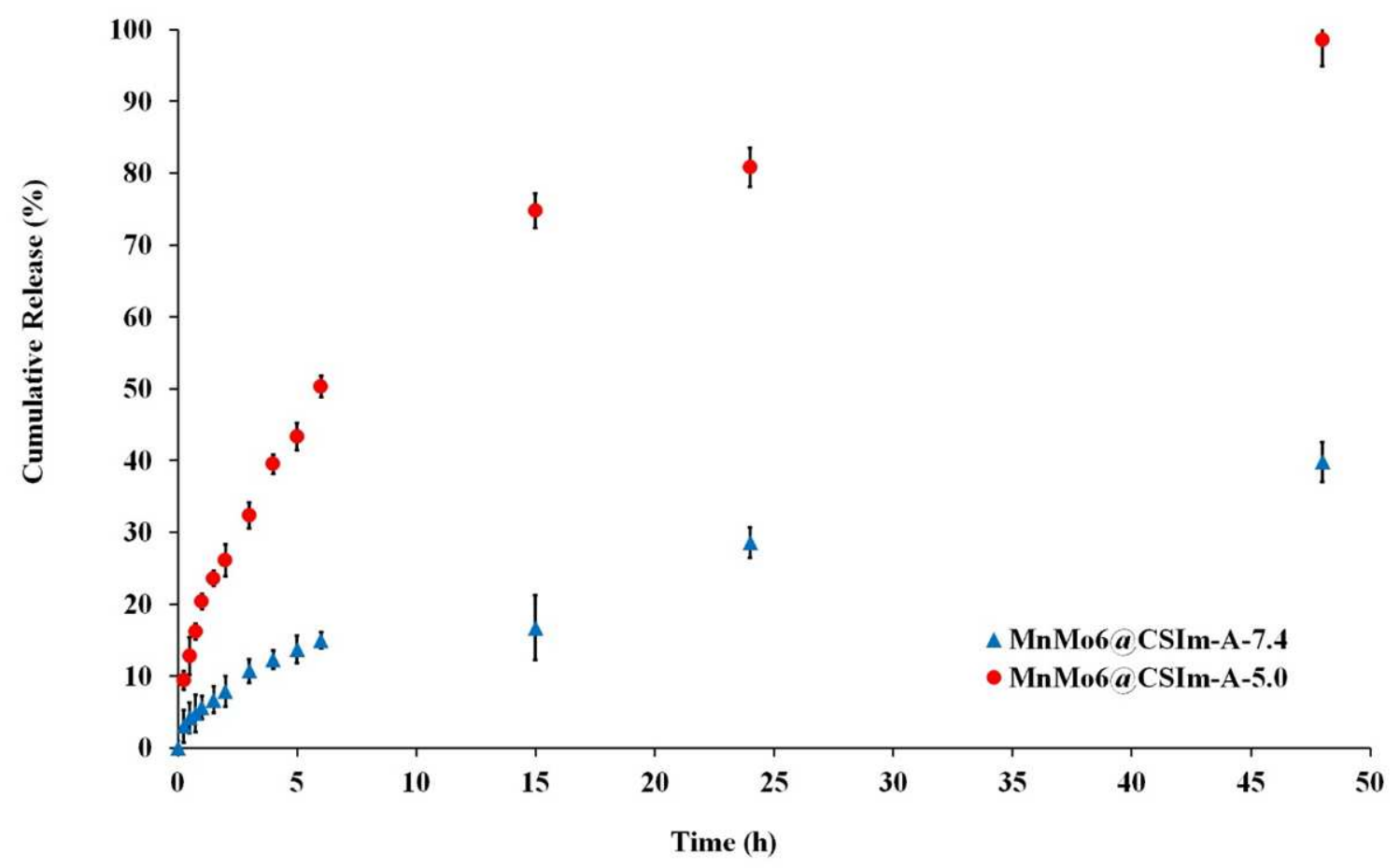

Figure 5. The release profile of MnMo6 from MnMo6@ CsIm at pH=7.4 and 5

\subsection{Biological Evaluations}

\subsubsection{In vitro colloidal stability}

Before any in vitro and in vivo evaluations, the colloidal stability of MnMo6@CSIm-A NCs should be checked in the related mediums. So, the cell culture media and blood serum were selected in this regard, and the particle size was monitored as the result. According to the DLS measurements, MnMo6@CSIm-A NCs showed good colloidal stability against aggregation in RPMI-FBS 15\% (Table 3) as the culture media. After $24 \mathrm{~h}$, the particle size of the NCs in the medium was increased by approximately $27 \%$, but still had a reasonable hydrodynamic size to be stable. As stated before, the increment in hydrodynamic size would be related to the water uptake and swelling behavior or partially absorption of medium component on the surface of NCs (63).

The minimum onset time of the anticancer effect for the POMs is about 12 hours and therefore the incubation time of 12 hours was chosen to evaluate the stability in the culture medium. In other words, the evaluated NCs are expected to remain stable in the culture medium for 12 hours so that they can enter the cancer cell through one of the up taking pathways. Assessment time for blood serum colloidal stability was 2 hours, which is the average blood circulation time for in vivo evaluations (64). According to the obtained results, the prepared nanocomposites have good colloidal stability for further evaluations. 
Table 3. The hydrodynamic size of MnMo6@SPB micelle in RPMI-FBS $15 \%$ solution at different time; all of measurements were done with sonication

\begin{tabular}{|c|c|}
\hline Evaluation in completed culture media \\
\hline Incubation time & $\operatorname{size}(\mathbf{n m})$ \\
\hline 0 & $140.1 \pm 1.9$ \\
\hline $5 \mathrm{~h}$ & $165.3 \pm 2.1$ \\
\hline $12 \mathrm{~h}$ & $178.6 \pm 1.8$ \\
\hline Evaluation of hydrodynamic size in Blood Serum \\
\hline Incubation time & $\operatorname{size}(\mathbf{n m})$ \\
\hline 0 & $140.1 \pm 1.9$ \\
\hline $1 \mathrm{~h}$ & $148.2 \pm 2.6$ \\
\hline $2 \mathrm{~h}$ & $159.4 \pm 2.1$ \\
\hline
\end{tabular}

\subsubsection{In vitro cytotoxicity assay}

The MTT assay was used to evaluate the cytotoxicity of MnMo6 and its nano-micellar forms on the triple-negative breast cancer cell line (MDA-MB-231) and MCF-7 in vitro. The half-maximal inhibitory concentrations $\left(\mathrm{IC}_{50}\right)$ for different groups were summarized in Table 4. Furthermore, the schematic comparison was provided in Figure 8 for two different cell lines.

Table 4. The IC50 values of free MnMo6 and its nanocomposite (MnMo6@CSIm-A) against breast cancer cell lines at two different incubation times

\begin{tabular}{|c|c|c|c|}
\hline Sample & Cell line & Incubation Time (h) & IC50 $(\boldsymbol{\mu g} / \mathbf{m l})$ \\
\hline \multirow{3}{*}{ Na-MnMo6 } & \multirow{2}{*}{ MCF-7 } & $\mathbf{2 4}$ & 195.3 \\
\cline { 2 - 4 } & & $\mathbf{4 8}$ & 180.2 \\
\cline { 2 - 4 } & MDA-MB-231 & $\mathbf{2 4}$ & 215.2 \\
\cline { 2 - 4 } & & $\mathbf{4 8}$ & 199.3 \\
\hline \multirow{3}{*}{ MnMo6@CSIm-A NCs } & \multirow{2}{*}{ MCF-7 } & $\mathbf{2 4}$ & 153.7 \\
\cline { 2 - 4 } & & $\mathbf{4 8}$ & 129.2 \\
\cline { 2 - 4 } & & $\mathbf{2 4}$ & 160.4 \\
\hline
\end{tabular}

As table 4 depicts, in both cancerous cell lines, MnMo6 and MnMo6@CSIm-A NCs exhibited time-dependent cytotoxicity effects, as it can be seen, the values of IC50s are reduced in longer incubation times, it can be related to the lower cellular uptake or the possible mechanisms of anticancer activity which maybe start in delay. However, there is no supportive information around this issue, in most studies, the incubation times usually are prolonged even to $72 \mathrm{~h}$ to get proper results (65). Another finding from the same table and figure 6 was the lower cytotoxicity of treated groups on the MDA-MB-231 cell line, which undoubtedly related to the lower sensitivity of this cell line. MDA-MB-231 cell line routinely is considered as the metastatic chemo-resistant type of 
breast cancer (66). This low efficacy is compensated to an acceptable level at higher doses and there is a significant difference in the toxicity behavior of the two systems.

As figure 6 depicts, the anticancer activity of both compounds (free MnMo6 \& MnMo6@CSImA NCs) is also dose dependent, and as the concentration increases the cell survival decrease, in both cell line the same trend of dose responding was approved. Another finding is related to the better cytotoxicity profile of NCs versus the free drug, as an important point, it seems that nanoformulation has facilitated cell entry compare to the free MnMo6. As the concentration reaches to $200 \mu \mathrm{g} / \mathrm{mL}$, the difference in effectiveness of the two categories (MnMo6 \& MnMo6@CSIm-A NCs) becomes quite significant. $\left(\mathrm{P}_{\text {value }}<0.001\right)$ on MCF-7 cell line. Since the loading content of MnMo6 in NCs in the best optimized conditions was about 45\%, so it seems that in lower concentrations in MTT assay the drug content does not reach the therapeutic dose, but better cell penetration helps the NCs to show relatively similar cytotoxicity. In higher concentrations (>100 $\mu \mathrm{g} / \mathrm{mL}$ ) the results support the beneficial aspects of nano drug delivery approach for MnM6 cytotoxic. The better cytotoxicity profile (lower IC50s) of prepared NCs in compare to the free MnMo6 is the first hypothesis of this study which confirmed by MTT results on MCF-7 and MDAMB-231 cell lines.

Other valuable result was obtained on normal HUVEC cells, as shown in Figure 7 the cytotoxicity of MnMo6 and MnMo6@SPB on HUVEC at different concentrations (50, 100, 150, and 200 $\mathrm{mg} / \mathrm{mL}$ ) were evaluated in compare to the Cis-Platin. In all concentrations, especially at concentrations close to the IC50 of MnMo6, we have a significant difference in the results of cytotoxicity on cancerous and normal cell lines. In the other words, despite the higher cytotoxicity on cancerous cells, the prepared NCs are safer than the free MnMo6 and Cis-platin on HUVEC normal cells. In this manner, the therapeutic doses could be adjusted to provide better cytotoxicity profile and lower side effects. The same results were provided by others on HUVEC cells for POMs nano formulations compared to the free POMs $(67,68)$. Based on these results, the second hypothesis of this study was confirmed, and such a promising result encourages studies in the preclinical phases of breast cancer researches. 
MCF-7 Cell line

$\square$ MnMo6 $\square$ MnMo6@CSIm-A NCs $\square$ CSIm-TPP NCs $\square$ control

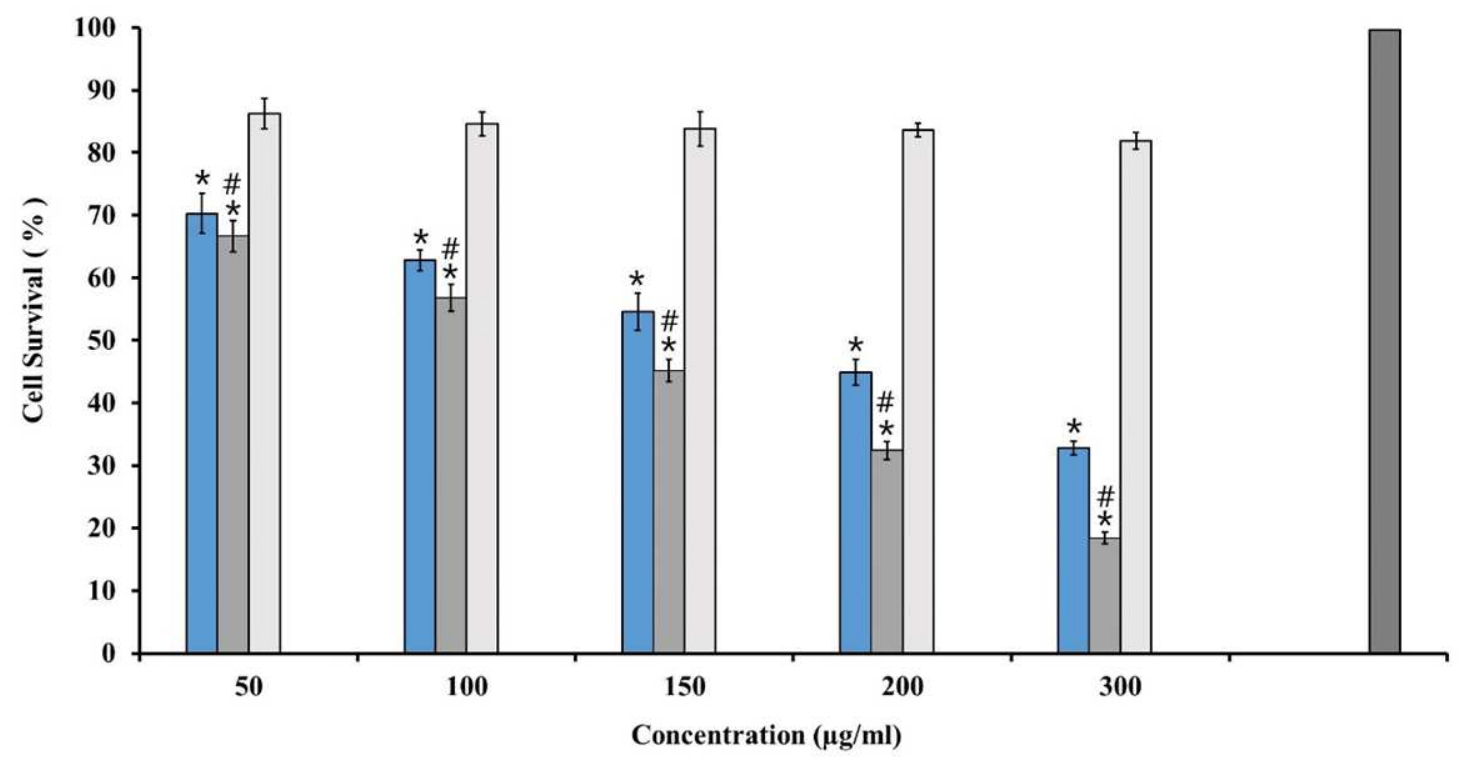

MDA-MB-231 cell line

口MnMo6 $\square$ MnMo6@CSIm-A NCs $\square$ CSIm-TPP NCs $\square$ Control

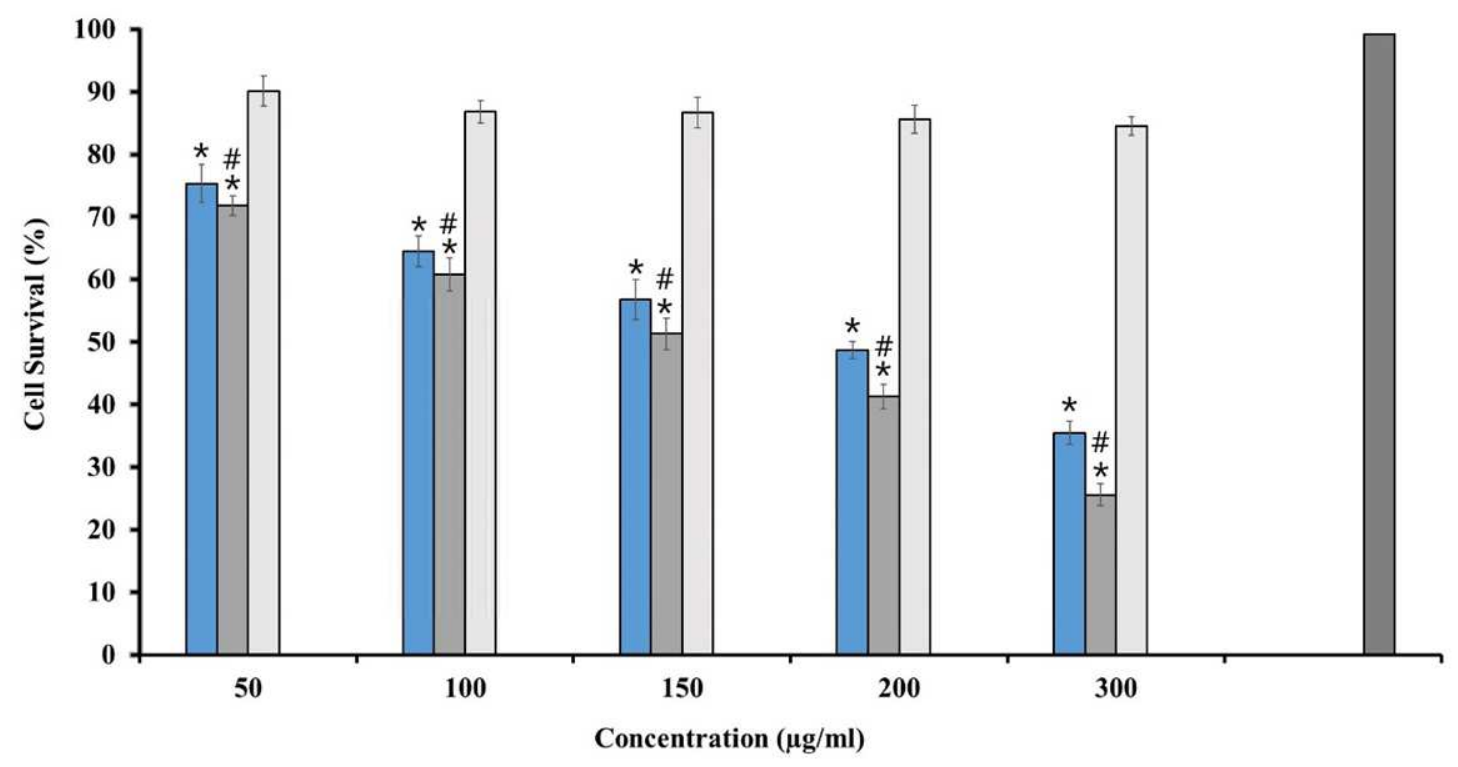

Figure 6. Cell cytotoxicity after $48 \mathrm{~h}$ incubation of free MnMo6, blank CSIm-TPP NCs, and MnMo6@CSImA NCs on breast cancer cell lines (MCF-7 and MDA-MB-231). Error bars represent SD, * depicts the significant difference with blank $P<0.05$, and \# depicts the significant difference between free MnMo6 and MnMo6@CSIm-A NCs 


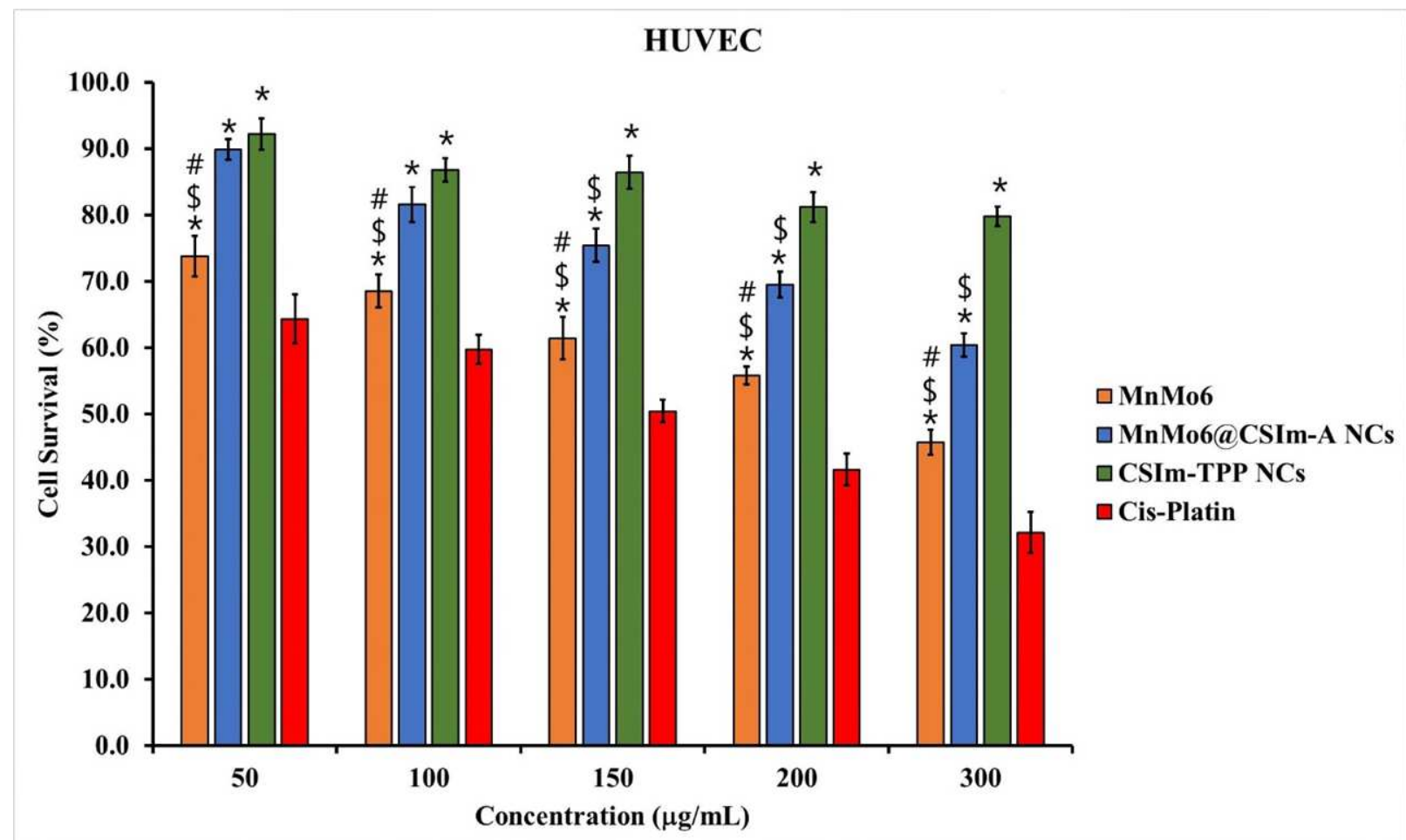

Figure 7. Cell cytotoxicity after $48 \mathrm{~h}$ incubation with free MnMo6, MnMo6@ CSIm-A NCs, blank CSIm-TPP NCs, and Cis-Platin at different concentrations on HUVEC normal cell line. Error bars represent SD, * means the significant difference with Cis-Platin, \$ means the significant difference with blank NCs, \# means the significant difference between two MnMo6 and MnMo6@CSIm-A NCs

\subsubsection{Analysis of cellular uptake}

Considering the chemo-resistance of MDA-MB-231 cell line, for cellular uptake, apoptosis, and cell migration evaluations this cell line was selected. Cellular uptake is one of those concerns regarding therapeutic efficiency of nanoparticles. Nanoparticulate delivery systems should be up taken by target cells before any biological activity onset. In the case of POMs, it always has been questioned if the high IC50s is related to cellular uptake or any intracellular mechanism $(69,70)$. In our recent study, we have successfully approved the efficacy of nanomicelles in delivery of POMs to cancer cells, and it was confirmed that the cellular uptake in the case of nano micellar formulation was interestingly higher than the free POMs (48). So, to evaluate the efficiency of subjected NCs of present study to pass through the cell membrane, the cellular content of molybdenum (Mo) was measured by ICP-MS as representative of MnMo6. In NCs The measured values of Mo into cells were normalized to the total protein content of the cells $(\mu \mathrm{g}$ Mo per mg cellular protein, Table 5.

The MDA-MB-231 cells were treated with free MnMo6 and MnMo6@CSIm-A NCs (300 $\mu \mathrm{g} / \mathrm{mL}$ ), and after a known procedure, the Mo content was measured by inductively-coupled plasma massspectrometry (ICP-MS) (71). Based on the ICP-MS results, almost all of MnMo6@CSIm-A NCs 
have entered and accumulated in cells, whereas in the case of free MnMo6, it seems that just about $58 \%$ of drugs could penetrate and accumulated in cells. Regarding the loading content percent of MnMo6 which is about $45 \%$, at concentration of $300 \mu \mathrm{g} / \mathrm{mL}$ the drug total content was about 150 $\mu \mathrm{g} / \mathrm{mL}$. So if all of NCs penetrate into the cells, the theoretical ratio of Mo weight ( $\mu \mathrm{g})$ to protein (mg) should be about 17.1, and interestingly the experimental ratio was 16.9. In the case of free MnMo6, the theoretical ratio with considering full uptake should be about 31.3, but the experimental result was about 18.2 that confirmed a cellular uptake about $58 \%$.

Based on the results MnMo6 suffers from relatively poor accumulation in cell, which fortunately overcome by using NCs instead of free MnMo6. In this regard, it is necessary to pay attention to the fact that, although the drug content of nanocomposites at a concentration of 300 is definitely lower than the free drug, but better permeability and cell entry has led to a significant increase in molybdenum content compared to the free drug.

Table 5. Molybdenium contents in MDA-MB-231 cells incubated for $24 \mathrm{~h}$ at concentrations of $90 \mathrm{and} 200 \mu \mathrm{g} / \mathrm{mL}$ of MnMo6 and MnMo6@SPB micelles respectively

\begin{tabular}{|l|l|l|l|l|l|}
\hline \multirow{2}{*}{ Sample } & \multirow{2}{*}{$\begin{array}{c}\text { Concentration } \\
(\mu \mathrm{g} / \mathrm{mL})\end{array}$} & \multirow{2}{*}{$\begin{array}{c}\text { Total protein } \\
(\mathrm{mg})\end{array}$} & \multicolumn{2}{c|}{$\begin{array}{c}\text { Mo content } \\
(\mu \mathrm{g} / \mathrm{mg} \text { of protein })\end{array}$} & \multirow{2}{*}{$\begin{array}{c}\text { Cellular uptake } \\
(\%)\end{array}$} \\
\cline { 3 - 6 } & & & Theoretical & Found & \\
\hline MnMo6 & 300 & 4.6 & 31.3 & 18.2 & 58.1 \\
\hline MnMo6@CSIm-A NCs & 300 & 4.2 & 17.1 & 16.9 & 98.8 \\
\hline Control & - & 5 & 0 & 0 & 0 \\
\hline
\end{tabular}

\subsubsection{Apoptosis analysis}

Apoptosis is one of those phenomenon in which the cells start to die in a programmed mechanism. During apotosis several changes in morphology of cells including chromatin condensation and fragmentation have occurred (72). Activation of apoptosis pathways by an anti-cancer agent is a valuable feature that always researchers look for. The apoptotic effects of MnMo6 and MnMo6@CSIm-A NCs were investigated using flow cytometry after staining with annexin V and propidium iodide (PI). The results are provided in figure 8, the upper left and right quadrant (Q1 and Q2) exhibit necrosis (positive for PI) and the late apoptosis (positive for PI and annexin), respectively and the lower right quadrant (Q3) show the apoptosis (positive for annexin). As shown in Figure 8, the MDA-MB231 cells that treated with MnMo6@CSIm-A NCs at concentration of $200 \mu \mathrm{g} / \mathrm{mL}$ (contaning $95 \mu \mathrm{g} / \mathrm{mL}$ of MnMo6) after $24 \mathrm{~h}$ compared to the control exhibited apoptosis of $81 \%$. MnMo6 at the same concentration $(95 \mu \mathrm{g} / \mathrm{mL})$ and incubation time did not induce apoptosis significantly (about 15.7\%). Other study by Yong etal. (73) has shown the comparable results for CS nanoparticles containing gadolinium deca-tungstate polyoxometalate on Hela and BEL-7402 cell lines. As an excellent satisfying result, the MnMo6@CSIm-A NCs can induce it anti-cancer activity via cell apoptosis induction which is a promising target for cancer therapy (74). 


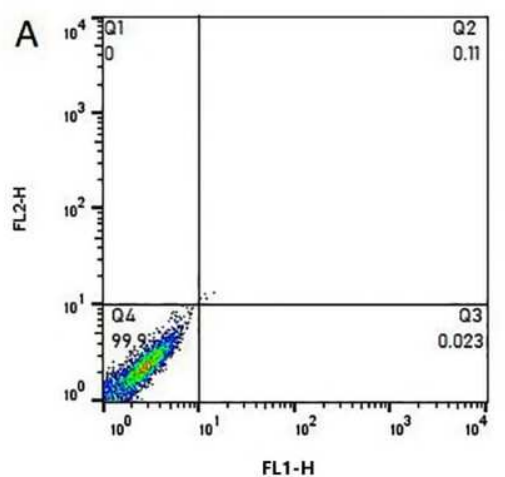

Control

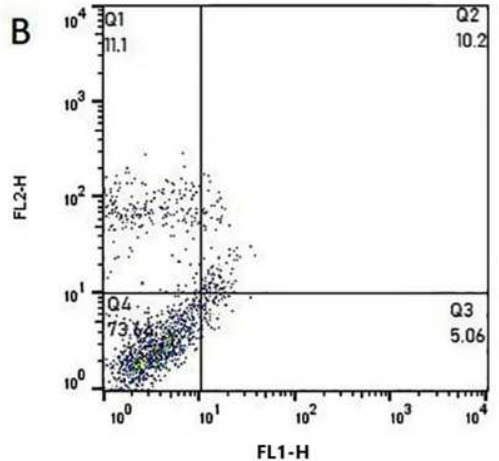

MnMo6

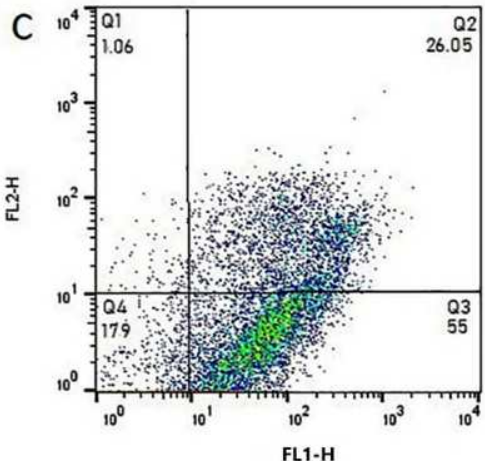

MnMo6@CSIm-A NCs

Figure 8. MnMo6@CSIm-A NCs induced apoptosis pathway in MDA-MB-231 breast cancer cells; flow cytometric analysis for control (a), MnMo6 (b) and MnMo6@SPB micelles (c)

\subsubsection{Cell migration assay}

Metastasis is the leading cause of cancer mortality. Given that migration and invasion ability are the most important features of a malignant tumor, Therefore, the study of cell migration and its effective factors and also the construction of compounds that play an inhibitory role in cell migration is valuable in drug development and cancer treatment (75). The scratch assay is an in vitro technique used to assess the contribution of molecular and cellular mechanisms to cell migration. The assay can also be used to evaluate therapeutic compounds before clinical use. It is done by making a scratch on a cell monolayer and capturing images at regular intervals by time lapse microscope (76).

In this study the effects of IC50 doses of MnMo6 as free or nano-formulation MnMo6@CSIm-A NCs were investigated on migration of MDAMB-231 breast cancer cell line at intervals of 3, 6, 12 and 24 hours, and the results were provided in figure 9. Our results showed that treatment of MDAMB-231 cells with IC50 dose of MnMo6@CSIm-A NCs leads to decreased cell migration by 1.4 -fold $(\mathrm{P}<0.05)$ compared to MnMo6 alone after $24 \mathrm{~h}$. In line with these data, the inhibitory effect of molybdenum nanoparticles on migration of normal cells has been reported (77), which is the only report on the study of molybdenum nanoparticles on cell migration. Therefore, the results of the present study, which is one of the pioneers in evaluating the migration inhibitory effect of POM NCs, can lead to the development of related studies in this field. 


\section{MDA-MB-231 cell migration assay}

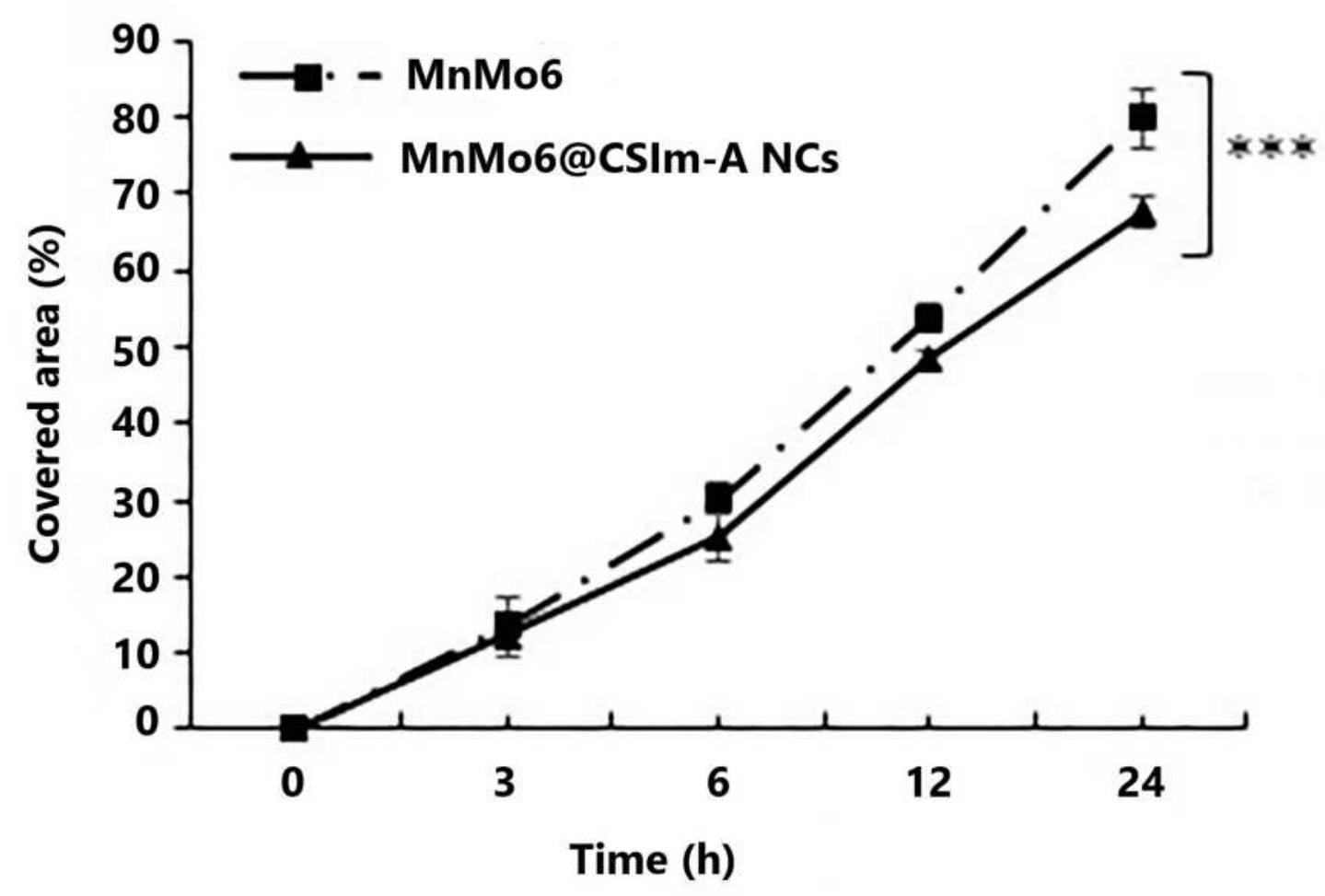

Figure 9: MDA-MB-231 cell migration assay upon treatment by MnMo6 \& MnMo6@CSIm-A NCs

\subsubsection{Red blood cell hemolysis}

Before any in vivo biomedical applications, it is so critical to evaluate the blood interaction as the first facing biological liquid. Based on evidences, the success in getting appropriate biodistribution and pharmacokinetics for ideal therapy is utterly dependent on hemocompatibility (45). RBC hemolysis assay is a valid test for measuring the safety of any biomaterial at ex vivo conditions (78). Nanoparticles may rupture RBC membrane and release the hemoglobin, which can be measured by UV-Vis. spectroscopy. Based on the obtained results (table 6), the MnMo6 induced RBC hemolysis with a rate of $24.5 \%$, whereas MnMo6@CSIm-A NCs did not show significant hemolysis $(<5 \%)$. So, it seems that the prepared NCs would be safe for any in vivo studies in the future.

Table 6: the hemolysis rate for MnMo6 \& MnMo6@CSIm-A NCs after 4h incubation

\begin{tabular}{|c|c|}
\hline Sample name & Hemolysis (\%) \\
\hline MnMo6 & $24.5 \pm 0.5$ \\
\hline MnMo6@CSIm-A & $2.25 \pm 0.8$ \\
\hline
\end{tabular}




\section{CONCLUSION}

Polyoxometalates, as potential anticancer agents, suffer from their high IC50s and normal cell cytotoxicity. One of the best strategies to overcome these issues is nano-drug delivery. In this regard, we introduced a novel anti-cancer polyoxometalate nanocomposite (MnMo6@CSIm) based on Anderson type polyoxomolybdate. The outcome of the present study indicated that the nanocomposite formula could enhance the cytotoxicity, cellular uptake, and apoptosis ratio in breast cancer cell line to high extent. Furthermore, the designed nanocomposite decreased the normal cell cytotoxicity to much extent along with non-hemotoxicity. The ability to decrease the cell migration in an invasive triple negative breast cancer cell line (MDA-MB-231) is the last special outcome of this study.

In Conclusion, this interesting nanocomposite structure with spherical morphology and suitable colloidal stability would be a promising candidate for further pre-clinical evaluations in the field of breast cancer research.

\section{Declaration of competing interest}

The authors report no conflicts of interest.

\section{Acknowledgment}

The authors wish to thank the Research vice Chancellery of Isfahan University of Medical Sciences for supporting this work.

\section{Declaration of competing interest}

The authors report no conflicts of interest.

\section{References}

1. Sung H, Ferlay J, Siegel RL, Laversanne M, Soerjomataram I, Jemal A, et al. Global Cancer Statistics 2020: GLOBOCAN Estimates of Incidence and Mortality Worldwide for 36 Cancers in 185 Countries. CA: A Cancer Journal for Clinicians. 2021;71(3):209-49.

2. Hassan M, Ansari J, Spooner D, Hussain S. Chemotherapy for breast cancer. Oncology reports. 2010;24(5):1121-31.

3. Zugazagoitia J, Guedes C, Ponce S, Ferrer I, Molina-Pinelo S, Paz-Ares L. Current challenges in cancer treatment. Clinical therapeutics. 2016;38(7):1551-66.

4. Bijelic A, Aureliano M, Rompel A. Polyoxometalates as potential next-generation metallodrugs in the combat against cancer. Angewandte Chemie International Edition. 2019;58(10):2980-99.

5. Yamase T. Polyoxometalates active against tumors, viruses, and bacteria. Biomedical inorganic polymers. 2013:65-116.

6. Blazevic A, Rompel A. The Anderson-Evans polyoxometalate: From inorganic building blocks via hybrid organic-inorganic structures to tomorrows "Bio-POM". Coordination Chemistry Reviews. 2016;307:42-64. 
7. Yamase T, Fujita H, Fukushima K. Medical chemistry of polyoxometalates. Part 1. Potent antitumor activity of polyoxomolybdates on animal transplantable tumors and human cancer xenograft. Inorganica Chimica Acta. 1988;151(1):15-8.

8. Čolović MB, Lacković M, Lalatović J, Mougharbel AS, Kortz U, Krstić DZ. Polyoxometalates in Biomedicine: Update and Overview. Current medicinal chemistry. 2020;27(3):362-79.

9. Geisberger G, Paulus S, Gyenge EB, Maake C, Patzke GR. Targeted delivery of polyoxometalate nanocomposites. Small. 2011;7(19):2808-14.

10. Mohammed MA, Syeda J, Wasan KM, Wasan EK. An overview of chitosan nanoparticles and its application in non-parenteral drug delivery. Pharmaceutics. 2017;9(4):53.

11. Lu B, Zhou G, Xiao F, He Q, Zhang J. Stimuli-responsive poly (ionic liquid) nanoparticles for controlled drug delivery. Journal of Materials Chemistry B. 2020;8(35):7994-8001.

12. Bielas R, Mielańczyk A, Skonieczna M, Mielańczyk $九$, Neugebauer D. Choline supported poly (ionic liquid) graft copolymers as novel delivery systems of anionic pharmaceuticals for antiinflammatory and anti-coagulant therapy. Scientific reports. 2019;9(1):1-12.

13. Shakeela K, Silpa G, Rayala SK, Rao GR. Polyoxometalate entrapped caprolactam gels and their cytotoxicity study. Journal of Chemical Sciences. 2018;130(8):1-6.

14. Zhou J, Zhao W, Miao Z, Wang J, Ma Y, Wu H, et al. Folin-Ciocalteu Assay Inspired

Polyoxometalate Nanoclusters as a Renal Clearable Agent for Non-Inflammatory Photothermal Cancer Therapy. ACS nano. 2020;14(2):2126-36.

15. Kumari $\mathrm{P}$, Ghosh B, Biswas S. Nanocarriers for cancer-targeted drug delivery. Journal of drug targeting. 2016;24(3):179-91.

16. Rodrigues S, Dionísio M, López CR, Grenha A. Biocompatibility of chitosan carriers with application in drug delivery. Journal of functional biomaterials. 2012;3(3):615-41.

17. M Ways TM, Lau WM, Khutoryanskiy VV. Chitosan and its derivatives for application in mucoadhesive drug delivery systems. Polymers. 2018;10(3):267.

18. Ali SA, Singh RP. Synthesis and Characterization of a Modified Chitosan. Macromolecular Symposia. 2009;277(1):1-7.

19. Omer AM, Ziora ZM, Tamer TM, Khalifa RE, Hassan MA, Mohy-Eldin MS, et al. Formulation of quaternized aminated chitosan nanoparticles for efficient encapsulation and slow release of curcumin. Molecules. 2021;26(2):449.

20. Yang T-T, Wen B-F, Liu K, Qin M, Gao Y-Y, Ding D-J, et al. Cyclosporine A/porous quaternized chitosan microspheres as a novel pulmonary drug delivery system. Artificial cells, nanomedicine, and biotechnology. 2018;46(sup2):552-64.

21. Mourya V, Inamdar NN. Trimethyl chitosan and its applications in drug delivery. Journal of Materials Science: Materials in Medicine. 2009;20(5):1057.

22. Fiorani G, Saoncella O, Kaner P, Altinkaya S, Figoli A, Bonchio M, et al. Chitosan-polyoxometalate nanocomposites: synthesis, characterization and application as antimicrobial agents. Journal of Cluster Science. 2014;25(3):839-54.

23. Croce M, Conti S, Maake C, Patzke GR. Nanocomposites of polyoxometalates and chitosan-based polymers as tuneable anticancer agents. European Journal of Inorganic Chemistry. 2019;2019(3-4):348-

56.

24. Shah HS, Al-Oweini R, Haider A, Kortz U, lqbal J. Cytotoxicity and enzyme inhibition studies of polyoxometalates and their chitosan nanoassemblies. Toxicology reports. 2014;1:341-52.

25. Fuchs J, Brüdgam I. Darstellung und Eigenschaften des Tetrabutylammonium-iso-oktamolybdats [N (C4H9) 4] 4Mo8O26/Preparation and Properties of Tetrabutylammonium iso-octamolybdate [N (C4H9) 4] 4Mo8O26. Zeitschrift für Naturforschung B. 1977;32(8):853-7.

26. Gündüz T, Gündüz N, Şakiyan I. A New Method for Synthesis of Manganese(III) Acetate Dihydrate. Synthesis and Reactivity in Inorganic and Metal-Organic Chemistry. 1994;24(4):519-24. 
27. Marcoux PR, Hasenknopf B, Vaissermann J, Gouzerh P. Developing remote metal binding sites in heteropolymolybdates. European Journal of Inorganic Chemistry. 2003;2003(13):2406-12.

28. Hosseini MS, Javanmard SH, Dana N, Rafiee L, Rostami M. Novel Tocopherol Succinate-

Polyoxomolybdate Bioconjugate as Potential Anti-Cancer Agent. Journal of Inorganic and Organometallic Polymers and Materials. 2021:1-13.

29. Rosnes MH, Yvon C, Long D-L, Cronin L. Mapping the synthesis of low nuclearity polyoxometalates from octamolybdates to Mn-Anderson clusters. Dalton Transactions. 2012;41(33):10071-9.

30. Sirviö JA, Visanko M, Liimatainen H. Synthesis of imidazolium-crosslinked chitosan aerogel and its prospect as a dye removing adsorbent. RSC advances. 2016;6(61):56544-8.

31. Maiti D, Zhong J, Zhang Z, Zhou H, Xion S, Dong Z, et al. Polyoxomolybdate (POM) nanoclusters with radiosensitizing and scintillating properties for low dose $X$-ray inducible radiation-radiodynamic therapy. Nanoscale Horizons. 2020;5(1):109-18.

32. Tan C, Liu N, Yu B, Zhang C, Bu W, Liu X, et al. Organic-inorganic hybrids formed by polyoxometalate-based surfactants with cationic polyelectrolytes and block copolymers. Journal of Materials Chemistry C. 2015;3(11):2450-4.

33. Carvalho PM, Felício MR, Santos NC, Gonçalves S, Domingues MM. Application of light scattering techniques to nanoparticle characterization and development. Frontiers in chemistry. 2018;6:237.

34. Varshosaz J, Sadri F, Rostami M, Mirian M, Taymouri S. Synthesis of pectin-deoxycholic acid conjugate for targeted delivery of anticancer drugs in hepatocellular carcinoma. International journal of biological macromolecules. 2019;139:665-77.

35. Selestin Raja I, Thangam R, Fathima NN. Polymeric micelle of a gelatin-oleylamine conjugate: a prominent drug delivery carrier for treating triple negative breast cancer cells. ACS Applied Bio Materials. 2018;1(5):1725-34.

36. Shah HS, Joshi SA, Haider A, Kortz U, lqbal J. Synthesis of chitosan-coated polyoxometalate nanoparticles against cancer and its metastasis. RSC advances. 2015;5(113):93234-42.

37. Moore TL, Rodriguez-Lorenzo L, Hirsch V, Balog S, Urban D, Jud C, et al. Nanoparticle colloidal stability in cell culture media and impact on cellular interactions. Chemical Society Reviews. 2015;44(17):6287-305.

38. Van Meerloo J, Kaspers GJ, Cloos J. Cell sensitivity assays: the MTT assay. Cancer cell culture: Springer; 2011. p. 237-45.

39. Ramezani-Aliakbari M, Soltanabadi A, Sadeghi-aliabadi H, Varshosaz J, Yadollahi B, Hassanzadeh $\mathrm{F}$, et al. Eudesmic acid-Polyoxomolybdate Organo-Conjugate as Novel Anticancer Agent. Journal of Molecular Structure. 2021:130612.

40. Kirin SI, Ott I, Gust R, Mier W, Weyhermüller T, Metzler-Nolte N. Cellular uptake quantification of metalated peptide and peptide nucleic acid bioconjugates by atomic absorption spectroscopy. Angewandte Chemie International Edition. 2008;47(5):955-9.

41. Ott I, Schmidt K, Kircher B, Schumacher P, Wiglenda T, Gust R. Antitumor-active cobalt- alkyne complexes derived from acetylsalicylic acid: Studies on the mode of drug action. Journal of medicinal chemistry. 2005;48(2):622-9.

42. Shi J, Liu S, Yu Y, He C, Tan L, Shen Y-M. RGD peptide-decorated micelles assembled from polymer-paclitaxel conjugates towards gastric cancer therapy. Colloids and Surfaces B: Biointerfaces. 2019;180:58-67.

43. Pimpão C, da Silva IV, Mósca AF, Pinho JO, Gaspar MM, Gumerova NI, et al. The aquaporin-3inhibiting potential of polyoxotungstates. International journal of molecular sciences. 2020;21(7):2467.

44. Yu L-Y, Su G-M, Chen C-K, Chiang Y-T, Lo C-L. Specific cancer cytosolic drug delivery triggered by reactive oxygen species-responsive micelles. Biomacromolecules. 2016;17(9):3040-7. 
45. Zamani M, Naderi E, Aghajanzadeh M, Naseri M, Sharafi A, Danafar H. Co1-XZnxFe2O4 based nanocarriers for dual-targeted anticancer drug delivery: Synthesis, characterization and in vivo and in vitro biocompatibility study. Journal of Molecular Liquids. 2019;274:60-7.

46. Lin C-G, Chen W, Long D-L, Cronin L, Song Y-F. Step-by-step covalent modification of Crtemplated Anderson-type polyoxometalates. Dalton Transactions. 2014;43(23):8587-90.

47. Pan C, Qian J, Zhao C, Yang H, Zhao X, Guo H. Study on the relationship between crosslinking degree and properties of TPP crosslinked chitosan nanoparticles. Carbohydrate Polymers.

2020;241:116349.

48. Ramezani-Aliakbari M, Varshosaz J, Sadeghi-Aliabadi H, Hassanzadeh F, Rostami M. BiotinTargeted Nanomicellar Formulation of an Anderson-Type Polyoxomolybdate: Synthesis and In Vitro Cytotoxicity Evaluations. Langmuir. 2021.

49. Yang H-K, Cheng Y-X, Su M-M, Xiao Y, Hu M-B, Wang W, et al. Polyoxometalate-biomolecule conjugates: A new approach to create hybrid drugs for cancer therapeutics. Bioorganic \& medicinal chemistry letters. 2013;23(5):1462-6.

50. Suo H, Gao Z, Xu L, Xu C, Yu D, Xiang X, et al. Synthesis of functional ionic liquid modified magnetic chitosan nanoparticles for porcine pancreatic lipase immobilization. Materials Science and Engineering: C. 2019;96:356-64.

51. Salazar Marcano DE, Lentink S, Moussawi MA, Parac-Vogt TN. Solution Dynamics of Hybrid Anderson-Evans Polyoxometalates. Inorganic Chemistry. 2021.

52. Sakamoto J, Annapragada A, Decuzzi P, Ferrari M. Antibiological barrier nanovector technology for cancer applications. Expert opinion on drug delivery. 2007;4(4):359-69.

53. Honary S, Zahir F. Effect of zeta potential on the properties of nano-drug delivery systems-a review (Part 2). Tropical Journal of Pharmaceutical Research. 2013;12(2):265-73.

54. Jelonek K, Zajdel A, Wilczok A, Latocha M, Musiał-Kulik M, Foryś A, et al. Dual-targeted biodegradable micelles for anticancer drug delivery. Materials Letters. 2019;241:187-9.

55. Wang J, Huang N, Peng Q, Cheng X, Li W. Temperature/pH dual-responsive and luminescent drug carrier based on PNIPAM-MAA/lanthanide-polyoxometalates for controlled drug delivery and imaging in HeLa cells. Materials Chemistry and Physics. 2020;239:121994.

56. Bu W, Uchida S, Mizuno N. Micelles and Vesicles Formed by Polyoxometalate-Block Copolymer Composites. Angewandte Chemie International Edition. 2009;48(44):8281-4.

57. Zhang L, Li H, Wu L. Noncovalent fabrication and tunable fusion of block copolymer-giant polyoxometalate hybrid micelles. Soft Matter. 2014;10(35):6791-7.

58. Dora CP, Singh SK, Kumar S, Datusalia AK, Deep A. Development and characterization of nanoparticles of glibenclamide by solvent displacement method. Acta pol pharm. 2010;67(3):283-90.

59. Geisberger G, Paulus S, Carraro M, Bonchio M, Patzke GR. Synthesis, Characterisation and Cytotoxicity of Polyoxometalate/Carboxymethyl Chitosan Nanocomposites. Chemistry - A European Journal. 2011;17(16):4619-25.

60. Kato Y, Ozawa S, Miyamoto C, Maehata Y, Suzuki A, Maeda T, et al. Acidic extracellular microenvironment and cancer. Cancer cell international. 2013;13(1):1-8.

61. Kanamala M, Wilson WR, Yang M, Palmer BD, Wu Z. Mechanisms and biomaterials in pHresponsive tumour targeted drug delivery: a review. Biomaterials. 2016;85:152-67.

62. Ko J, Park K, Kim Y-S, Kim MS, Han JK, Kim K, et al. Tumoral acidic extracellular pH targeting of $\mathrm{pH}$-responsive MPEG-poly ( $\beta$-amino ester) block copolymer micelles for cancer therapy. Journal of Controlled Release. 2007;123(2):109-15.

63. Abstiens K, Figueroa SM, Gregoritza M, Goepferich AM. Interaction of functionalized nanoparticles with serum proteins and its impact on colloidal stability and cargo leaching. Soft Matter. 2019;15(4):709-20. 
64. Li W, Yi X, Liu X, Zhang Z, Fu Y, Gong T. Hyaluronic acid ion-pairing nanoparticles for targeted tumor therapy. Journal of Controlled Release. 2016;225:170-82.

65. Modugno G, Fabbretti E, Dalle Vedove A, Da Ros T, Maccato C, Hosseini HS, et al. Tracking fluorescent polyoxometalates within cells. European Journal of Inorganic Chemistry. 2018;2018(46):4955-61.

66. Holliday DL, Speirs V. Choosing the right cell line for breast cancer research. Breast cancer research. 2011;13(4):1-7.

67. Sun T, Cui W, Yan M, Qin G, Guo W, Gu H, et al. Target Delivery of a Novel Antitumor Organoplatinum (IV)-Substituted Polyoxometalate Complex for Safer and More Effective Colorectal Cancer Therapy In Vivo. Advanced Materials. 2016;28(34):7397-404.

68. Shi Y, Zhang J, Huang H, Cao C, Yin J, Xu W, et al. Fe-doped Polyoxometalate as acid-aggregated Nanoplatform for NIR-II Photothermal-enhanced Chemodynamic therapy. Advanced healthcare materials. 2020;9(9):2000005.

69. Xiao H, Wu B, Xue C, Wang F. Two new polyoxometalate-based transition metal complexes inhibit bladder cancer cell growth via mitochondrial apoptotic pathway. Journal of Coordination Chemistry. 2019.

70. Geisberger G, Gyenge EB, Hinger D, Bösiger P, Maake C, Patzke GR. Synthesis, characterization and bioimaging of fluorescent labeled polyoxometalates. Dalton transactions. 2013;42(27):9914-20.

71. Kruszewska J, Kur A, Kulpińska D, Grabowska-Jadach I, Matczuk M, Keppler BK, et al. An improved protocol for ICP-MS-based assessment of the cellular uptake of metal-based nanoparticles. Journal of pharmaceutical and biomedical analysis. 2019;174:300-4.

72. Ashkenazi A. Targeting the extrinsic apoptosis pathway in cancer. Cytokine \& growth factor reviews. 2008;19(3-4):325-31.

73. Yong Y, Zhang C, Gu Z, Du J, Guo Z, Dong X, et al. Polyoxometalate-based radiosensitization platform for treating hypoxic tumors by attenuating radioresistance and enhancing radiation response. ACS nano. 2017;11(7):7164-76.

74. Pfeffer CM, Singh AT. Apoptosis: a target for anticancer therapy. International journal of molecular sciences. 2018;19(2):448.

75. Tahtamouni L, Ahram M, Koblinski J, Rolfo C. Molecular regulation of cancer cell migration, invasion, and metastasis. Hindawi; 2019.

76. Liang C-C, Park AY, Guan J-L. In vitro scratch assay: a convenient and inexpensive method for analysis of cell migration in vitro. Nature protocols. 2007;2(2):329.

77. Zheng W, Yang L, Liu Y, Qin X, Zhou Y, Zhou Y, et al. Mo polyoxometalate nanoparticles inhibit tumor growth and vascular endothelial growth factor induced angiogenesis. Science and technology of advanced materials. 2014;15(3):035010.

78. Wolf M, Anderson J. Practical approach to blood compatibility assessments: General considerations and standards. Biocompatibility and performance of medical devices: Elsevier; 2020. p. 167-205. 